九州大学学術情報リポジトリ

Kyushu University Institutional Repository

\title{
Influences of hydrogen on deformation and fracture behaviors of high Zn 7XXX aluminum alloys
}

Bhuiyan, Md. Shahnewaz

Department of Mechanical Engineering, Kyushu University

Tada, Yuki

Department of Mechanical Engineering, Kyushu University : Graduate Student

Toda, Hiroyuki

Department of Mechanical Engineering, Kyushu University

Hang, Su

Department of Mechanical Engineering, Kyushu University

他

http://hdl. handle. net/2324/1812451

出版情報: International Journal of Fracture. 200 (1/2)，pp. 13-29，2016-02-22 バージョン：

権利関係 : 


\section{Influences of hydrogen on deformation and fracture behaviors of high $\mathrm{Zn} \mathrm{7XXX}$ aluminum}

\section{alloys}

Md. Shahnewaz Bhuiyan*a ${ }^{\mathrm{a}}$, Yuki Tada ${ }^{\mathrm{b}}$, Hiroyuki Toda ${ }^{\mathrm{c}}, \mathrm{Su} \mathrm{Hang}^{\mathrm{d}}$, Kentaro Uesugi ${ }^{\mathrm{e}}$, Akihisa Takeuchi $^{\mathrm{f}}$, Nobuto Sakaguchi ${ }^{\mathrm{g}}$, Yoshio Watanabe ${ }^{\mathrm{h}}$

*a Department of Mechanical Engineering, Kyushu University; e-mail: bhuiyan@mech.kyushuu.ac.jp

${ }^{\mathrm{b}}$ Graduate Student, Department of Mechanical Engineering, Kyushu University,

${ }^{c}$ Department of Mechanical Engineering, Kyushu University, e-mail: toda@mech.kyushuu.ac.jp

${ }^{\mathrm{e}}$ Doctoral Student, Department of Mechanical Engineering, Kyushu University

f Researcher, Japan Synchrotron Radiation Research Institute

${ }^{\mathrm{g}}$ Researcher, Japan Synchrotron Radiation Research Institute

${ }^{\mathrm{h}}$ Researcher, UACJ Co. Ltd.

${ }^{j}$ Researcher, UACJ Co. Ltd.; e-mail: watanabe-yoshio@uacj.co.jp

\section{Abstract}

Hydrogen degrades the mechanical properties of high strength 7XXX aluminum alloys in two ways: (i) degrades the mechanical properties by hydrogen embrittlement, and (ii) partitioned into micropores as molecular hydrogen and make contributions to ordinary ductile fracture. The multifaceted effects of hydrogen on the mechanical properties of high $\mathrm{Zn}$ content 7XXX aluminum alloys during deformation and fracture is studied by using synchrotron X-ray microtomography. Our results have revealed that the hydrogen susceptibility has increased with increasing the $\mathrm{Zn}$ amount. High concentration of hydrogen was induced by the EDM wire eroder. This high concentrated hydrogen induces quasi-cleavage fracture and restricts the growth of 
micropores during ductile deformation. The threshold concentration of hydrogen ahead of the crack tip for the nucleation of quasi-cleavage feature was estimated to be $13 \mathrm{~cm}^{3} / 100 \mathrm{~g} \mathrm{Al}$. Keywords Microtomography; Micropore; Synchrotron radiation; Hydrogen embrittlement; Aluminum alloys

\section{Introduction}

The Al-Zn-Mg-Cu (7XXX) series aluminum alloys are widely used in the aerospace industry owing to their superior mechanical properties coupled with specific stiffness, low cost, and machinability. In order to meet the raising demands of higher strength, fracture toughness, and improved stress corrosion cracking (SCC) resistance, a series of 7XXX aluminum alloys has been developed through changes in composition (mainly $\mathrm{Zn} / \mathrm{Mg} / \mathrm{Cu}$ ratios), heat treatments and processing (Koyama 2010). The strength of 7XXX alloys is mainly attributed to the presence of coherent $\eta^{\prime}$ phase $\left(\mathrm{MgZn}_{2}\right)$ in the grain interior and non-coherent $\eta$ phase along the grain boundaries (Immarigeon et al. 1995). Hence, higher Zn-Mg ratio not only increases the formation of $\mathrm{MgZn}_{2}$ that strengthens the alloys after a heat treatment but also makes the alloys prone to SCC (Chen et al. 2013). Gruhl and Metallkd (1984) reported that the SCC susceptibility of 7XXX aluminum alloys increases with increasing $\mathrm{Zn}$ content. The strength and toughness can be further elevated by the addition of dispersoids such as $\mathrm{Zr}, \mathrm{Sc}, \mathrm{Sn}, \mathrm{Mn}, \mathrm{Ag}$ that also increase the strength of the alloys (Rometsch et al. 2003; Seyed Ebrahimi et al. 2010; Milman et al. 2002).

It is now well documented that microstructural features (such as grain boundary precipitates, precipitate free zones, Guinier-Preston zones, micropores, etc.) in 7XXX series aluminum alloys depend on the type of aging treatments. The distribution and size of these microstructures not only affect the attainable strength and fracture toughness significantly but also plays a dominant 
role in SCC resistance of the alloys system. For example, increasing the size and spacing of the grain boundary precipitates (GBPs) decreased the SCC susceptibility (Adler et al. 1971). Moreover, the larger grain boundary precipitates can act as trapping sites for hydrogen. It is also reported that SCC resistance can be improved by increasing the size of grain boundary precipitates (Park and Ardell 1984).

Drawing the literature, two broad types of rationales on the operating mechanism for SCC of 7XXX series aluminum alloys have been identified (Ambat and Dwarakadasa 1990; Starke and Staleyt 1996). One suggested that the crack advances by anodic dissolution, where an electrochemical reaction takes control rather than hydrogen. The main controlling factors for anodic dissolution mechanism are GBPs size, spacing and/or volume fraction, matrix precipitate size/distribution (Starke and Staleyt 1996). On the other hand, the second mechanism postulates that the crack advances by hydrogen embrittlement (HE). The hydrogen-assisted fracture morphology in 7XXX aluminum alloys is frequently intergranular (Holroyd and Hardie 1981; Nguyen et al. 1987). Transgranular, a mixture of transgranular and intergranular, quasi-cleavage are, however, also observed as fractographic features of hydrogen related failure (Albrecht and Bernstein 1982; Truck 1985; Hardie et al. 1979; Meletis et al. 1991, Kamoutsi et al. 2006). The existence of these fracture modes is mainly influenced by the hydrogen fugacity (Gest and Troiano 1974; Thompson and Bernstein 1975; Thompson and Bernstein 1980), loading mode (Pickens et al. 1983), strain rate (Taheri et al. 1979; Holroyd and Hardie 1981), temperature (Albrecht et al. 1979) and microstructure (Albrecht et al. 1979; Nguyen et al. 1987). These factors all lead to a critical condition for hydrogen embrittlement through some specific mechanisms: hydride induced cracking (Balasubramaniam et al. 1991; Thakur and 
Balasubramaniam 1997), and hydrogen enhanced localized plasticity (HELP) (Bond et al. 1987; Zeides and Roman 1990).

More recently, Toda et al. $(2013 ; 2014)$ discovered the presence of micropores in all grades of aluminum alloys, and reported that hydrogen is partitioned in micropores in the form of molecular hydrogen. Under external loading, these micropores exhibited premature growth in the loading direction and makes a contribution to the ductile fracture.

Based on the aforementioned discussion, it is reasonable to assume that hydrogen influences the mechanical properties of aluminum alloys in two ways: (i) degrading the mechanical properties by hydrogen embrittlement, and (ii) partitioning into micropores as molecular hydrogen, which will be a dominant damage mechanism for ductile fracture.

The purpose of this study is of threefold: first to investigate the growth behavior of micropores during deformation process using state-of-the-art synchrotron X-ray microtomography; second to demonstrate the influence of dissolved hydrogen on the mechanical properties of aluminum alloys; finally to show that the HE phenomena in the present material can be treated within the framework of HELP mechanism.

\section{Experimental procedure}

\subsection{Material and specimen preparation}

Modified 7150 aluminum alloys (with 10 mass $\%$ Zn) and base 7150 aluminum alloys were used in the present study. Three alloys were prepared from the supplied modified 7150 aluminum alloys, where the composition of the materials remains same, but the amount of total hydrogen content is varied. Hereinafter, the materials are called material LH, material MH, and material $\mathrm{HH}$, respectively. The as-cast ingots were first homogenized at $743 \mathrm{~K}$ for $24 \mathrm{~h}$ followed by air cooling to room temperature. The ingots were then hot rolled with multiple passes at $673 \mathrm{~K}$. The 
final thickness of the ingots was $13 \mathrm{~mm}$. The rolled plates were then solution heat treated for $2 \mathrm{~h}$ at $748 \mathrm{~K}$ followed by cold water quenching and artificially aged at $393 \mathrm{~K}$ for $6 \mathrm{~h}$ to provide T7651 temper condition. The vacuum fusion method was utilized to measure the total hydrogen content of each material. The description of vacuum fusion method for analyzing the total hydrogen content in aluminum alloys is reported elsewhere (Imabayashi and Tomita 2014). Moreover, a thin plate of $0.3 \mathrm{~mm}$ has been cut from material $\mathrm{MH}$ by using an EDM wire eroder and the total hydrogen is also measured by using vacuum fusion method. Hereinafter, the material is called material MH_EDM.

Specimens (typically 0.6 (width, W), 0.6 (thickness, T) and 22 (length, L) mm) were machined from the rolled plate in the rolling direction by using an electrodischarge machine (EDM) wire eroder for in-situ microtomography tensile testing and ex-situ tensile testing and is shown in Fig. 1a. Room temperature tensile test specimens (22 (gauge length), 4 (gauge width), and 2 (thickness) mm) were also machined from the rolled plates (Fig. 1b). All the specimens were machined with tensile load applied in the rolling direction. Three-point bend specimens (typically 55 (length, L), 10 (width, W), and 10 (thickness, T) mm) were also machined from the supplied rolled plates for fracture toughness test and is shown in Fig. 1c.

\subsection{In-situ X-ray microtomography and tensile testing}

The in-situ tensile test was performed at BL20XU undulator beamline of SPring- 8 . The observation was carried out using a monochromatic X-ray beam with a photon energy of $20 \mathrm{keV}$, which is generated by a liquid nitrogen-cooled $\mathrm{Si}$ (111) double crystal monochromator. An image detector is placed $20 \mathrm{~mm}$ behind the specimen and consisted of $4000(\mathrm{H})$ by $2624(\mathrm{~V})$ element CMOS camera, a single-crystal scintillator $\left(\mathrm{Lu}_{2} \mathrm{SiO}_{5}: \mathrm{Ce}\right)$ and a lens (20×). Total 1800 
radiographs, scanning 180 degrees, were obtained around the loading axis in 0.1-degree increments for each load level.

The in-situ loading stage allowed specimens to be scanned under monotonic tensile loading. All the scans were performed while the loaded samples were being held at fixed displacements. The first tomography scan was performed without loading and then subsequent 10 scans for material $\mathrm{LH}$ and material $\mathrm{MH}$, and 9 scans for material $\mathrm{HH}$ were performed until the failure of the specimens. To suppress the occurrence of blurring caused by the relaxation behavior of the materials, the applied displacement was held for $15 \mathrm{~min}$ for aging before each scan. Image slices were reconstructed from a series of projections based on the conventional filtered back-projection algorithm. An isotropic voxel with a $0.5 \mu \mathrm{m}$ edge was achieved in the reconstructed slices. The gray value in each dataset was calibrated so that the linear absorption coefficient of -30 to $50 \mathrm{~cm}^{-1}$ fell within an 8-bit gray scale range between 0 to 255 . From the reconstructed CT images, micropores are segmented and the morphological characteristics of each micropore such as surface area, volume, the center of gravity are measured precisely. In order to minimize the sum of the distances between identical micropores captured during the two consecutive loading steps, a precise image registration is performed using a transformation matrix. Then the matching parameter method with the modified spring model is employed for tracking the micropores throughout the loading. The detailed description is outlined elsewhere (Kobayashi et al. 2008, Toda et al. 2011). To calculate the strain, tetrahedrons with vertices occupied by micropores were created by the Delaunay tessellation technique (Barber et al. 1996).Strains are calculated from the displacement of the tetrahedrons vertices, assuming a linear displacement field inside it. 


\subsection{Mechanical test}

The room temperature tensile tests, three specimens for each material, were carried out by using an Instron testing machine with a loading rate at $8.3 \times 10^{-3} \mathrm{~mm} / \mathrm{sec}$. Displacement measurement was carried out with Zimmer optical extensometer (Model $200 \mathrm{XH}$ ). The fracture toughness tests, three specimens for each material, were carried out using three-point bend specimens with $a / W$ ratio approximately 0.5 , where $a$ is the initial crack length and $W$ is the specimen width. Instead of fatigue pre-crack, a notch of $0.1 \mathrm{~mm}$ width was introduced by using ISOMET micro saw cutter to each fracture toughness specimen and the apparent fracture toughness value was calculated according to the linear fracture mechanics.

\section{Results}

\subsection{General mechanical properties}

Figure 2 shows the optical microstructure for all the alloys used in this study. Almost equiaxed, flat pancake shaped grains, elongated in the direction of rolling is observed. Three tensile tests were performed and corresponding three stress-strain curves were recorded for each material. A typical stress-strain curve is shown in Fig. 3a. To clearly see the effect of total hydrogen content on the tensile properties of the alloys, the related tensile properties of ultimate tensile strength and fracture strain are listed in Table 1 and illustrated in Fig. $3 b$ and Fig. $3 c$ with error bars. The results of tensile tests, based on three specimens for each material, showed that both ultimate tensile strength and fracture strain decreases linearly with increasing the total hydrogen content.

\subsection{Influence of hydrogen micropores}

\subsubsection{Initial microstructural features}

In-situ 2D radiographs in $\mathrm{XY}$ and $\mathrm{XZ}$ plane is shown in Fig. 4. The image is obtained at zero loading. Energy-dispersive X-ray spectometry revealed that the white color and black color 
phases to be $\mathrm{Al}_{7} \mathrm{Cu}_{2} \mathrm{Fe}$ particles and micropores (indicated by arrows), respectively. On this figure, it can be seen that the particles are irregular in shape. The maximum diameter of the particle is $14.82 \mu \mathrm{m}$ in material $\mathrm{LH}, 18.40 \mu \mathrm{m}$ in material $\mathrm{MH}$ and $19.90 \mu \mathrm{m}$ in material $\mathrm{HH}$, respectively. The variation in diameter and shape of particles are shown in Fig. 5. The majority of the particles diameter is less than $5 \mu \mathrm{m}$. The 3D distribution of micropores in each alloys is shown in Fig. 6. Hydrogen micropores in all the three groups of materials were nucleated heterogeneously. The quantitative results of hydrogen micropores obtained by image analysis are summarized in Table 2. Although average micropore size (2.70 and $2.90 \mu \mathrm{m}$ for materials LH and $\mathrm{MH}$, respectively) do not differ much between materials $\mathrm{LH}$ and $\mathrm{MH}$, material $\mathrm{MH}$ showed 4 times higher micropores volume fraction compared to that of material LH. The total hydrogen content and estimated trapped hydrogen in micropores are shown in Table 3 . It is noteworthy that material $\mathrm{MH}$ showed the significantly high amount of hydrogen is trapped in micropores (51\%) compared to that of material LH (33\%) and material HH (27.7\%). Moreover, the volume fraction of micropores showed a linear relationship with the total hydrogen content of the material. However, highly coarse micropores in material HH (Fig. 6) is observed, the largest diameter of which is $\mathbf{5 7 . 1 4}$ micrometer.

\subsubsection{Micropore growth behavior}

Fig. 7 shows a typical example of void initiation caused by $\mathrm{Al}_{7} \mathrm{Cu}_{2} \mathrm{Fe}$ particle fracture. Initiation and propagation of a crack are also identified in a series of tomographic slices. Fig. 8 shows the 3D distribution of micropores and microvoids (both highlighted in red) and nucleation and propagation of cracks (highlighted by yellow) within part of a rendered volume in materials LH, $\mathrm{MH}$, and $\mathrm{HH}$, respectively. Although, at this magnification, the micropore growth and coalescence behavior during loading is not so obvious, a considerable amount of microvoids has 
been generated just before the final fracture (Fig 8d). It is interesting to note that all the materials showed the nucleation and propagation of the crack. The strain at which crack nucleation was observed is $4.3 \%$ for material $\mathrm{LH}, 3.2 \%$ for material $\mathrm{MH}$, and $3.6 \%$ for material $\mathrm{HH}$, respectively, indicating that the crack nucleated at relatively early loading stage. 3D/4D quantitative measurements of micropore/void volume fraction and number density over the wholly applied strain range is shown in Fig. 9. The data for A2024-T3 aluminum alloys (Toda et al. 2013) is also shown in Fig. 9. Note that the total hydrogen content of LH-A2024 and $\mathrm{HH}-\mathrm{A} 2024$ aluminum alloys is $0.17 \mathrm{~cm}^{3} / 100 \mathrm{~g} \mathrm{Al}$ and $2.90 \mathrm{~cm}^{3} / 100 \mathrm{gAl}$, respectively. Compared to the present material $\mathrm{LH}$, the total hydrogen content is about 2.8 times higher in LH-A2024 aluminum alloys and 48 times higher in HH-A2024 aluminum alloys. Despite such a high level of hydrogen content, the pre-existing micropores in A2024 aluminum alloys showed a predominant growth in the loading direction from the onset of plastic deformation (Fig. 9a). However, the present investigated material showed a very limited growth in the loading direction (Fig. 9b).

The fracture mechanisms of the in-situ tested specimens were studied with the aid of a scanning electron microscope. A typical morphology of the fracture surface of the material MH specimen is shown in Fig. 10. Mainly two typical zones can be observed: at the center of the sample, the fracture mode was found to be ductile with equiaxed dimples (Fig. 10b), while quasi-cleavage fracture zone was found at the periphery (Fig. 10c and Fig. 10d). The quasi-cleavage fracture zone extended approximately $150 \mu \mathrm{m}$ into the material from the surface. Effect of hydrogen on various high strength and medium strength alloys have been investigated by a number of investigators (Koyama et al. 2013; Zhao et al. 2014; Takano 2008). Their studies have revealed that enhanced hydrogen concentration at the surface region has changed the 
fracture surface morphology from microvoid coalescence to quasi-cleavage fracture. Therefore, the existence of both quasi-cleavage and ductile fracture modes is a clear indication of the increased susceptibility of hydrogen in the present material.

Fig. 11 showed the fracture surface observation of base 7150 aluminum alloys. For comparison, the fracture surface of the material $\mathrm{MH}$ is also shown. It is interesting to see that the base 7150 aluminum alloys (6 mass \% $\mathrm{Zn}$ ) exhibited ductile fracture. As the amount of $\mathrm{Zn}$ is increased from 6 mass $\%$ to 10 mass $\%$, the fracture mode also changes and exhibited brittle region (quasicleavage feature) only very near to surface area and ductile mode with dimple pattern in the central region. However, both the base 7150 aluminum alloys and the modified 7150 aluminum alloys also showed intergranular failure in the form of elongated features. This investigation suggests that the hydrogen susceptibility has drastically increased with increasing the $\mathrm{Zn}$ amount.

\subsection{Influence of dissolved hydrogen}

\subsubsection{Hydrogen uptake and its influence on fracture toughness}

The measured total hydrogen content of the material MH_EDM is $7.85 \mathrm{~cm}^{3} / 100 \mathrm{gAl}$ (as shown in Table 3). This is 130 times, 49 times and 15 times higher compared to that of material LH, material $\mathrm{MH}$, and material $\mathrm{HH}$, respectively. During deformation, this high concentration of hydrogen nucleates crack from the onset of plastic deformation, restricts the micropore growth and dominate the damage mechanism process.

Fig. 12 shows the fracture toughness of standard test specimens obtained in three-point bending. The load-deflection curve is also shown in Fig. 12. A gradual increase in apparent fracture toughness $\left(K_{Q}\right)$ properties with decreasing total hydrogen content can be observed. Using the $K_{Q}$ and $\sigma_{y}$ values for material LH (56.14 MPa.m ${ }^{1 / 2}$ and 696.7 MPa, respectively), the plain strain criterion will be $B, a \geq 16.23 \mathrm{~mm}$. This clearly indicates that the $K_{Q}$ values obtained did not 
satisfy the plain strain condition. Therefore, the $K_{Q}$ values of the present alloys would be smaller than the $K_{Q}$ values obtained.

It has been reported that the crack tip opening displacement (CTOD) can be related to the stress intensity factor $\left(K_{I}\right)$ using the following formula (BS 7910):

$C T O D=\frac{K_{I}^{2}}{m \sigma_{Y} E^{\prime}}$

where, $K_{I}, \sigma_{Y}, E^{\prime}$, are the stress intensity factor, the yield strength, and effective modulus, respectively and $m$ is a constant that depends on specimen geometry and work hardening behavior. In general, $m$ lies in the range 1 and 2 .

Under plane stress condition (since the $K_{Q}$ values obtained in the present study did not satisfy the plane strain condition, hence plane stress condition is assumed), $m=1$ (Zhu and Joyce 2012) and the effective modulus is the plane stress modulus $\left(E^{\prime}=E\right.$, where $E$ is young's modulus for the material). Hence Eq. (1) reduces to

$C T O D=\frac{K_{I}^{2}}{\sigma_{Y} E}$

The critical crack tip opening displacement (CTOD) is directly measured from a 3D image, and the calculated apparent fracture toughness values are also shown in Fig. 13. Interestingly, the quasi-cleavage fractured specimens with showed significantly reduced fracture toughness properties, which is about 0.15 to 0.2 times than that of the standard test specimen.

It is worth nothing that in the present study, initially smooth tensile specimens that contain brittle defects in the subsequent loading steps were used to measure the fracture toughness values. Meanwhile, the specimens with brittle defects correspond to single-edge notched tension ( $\operatorname{SE}(T)$ ) specimens, that are not used for plane strain toughness measures. Furthermore, during the test, the entire section of the specimen deforms plastically, since the specimen is smaller than the 
plastic zone size. Therefore, the application of linear elastic fracture mechanics is no longer suitable as conditions of global plastic collapse are encountered. Generally, the fracture toughness values are typically determined by using single-edge notched bend (SE(B)) and compact tension $(\mathrm{C}(\mathrm{T}))$ specimens. ). It is also well recognized that the fracture toughness value depends on the crack tip constraints, whose magnitude depends on the crack length, the loading type and the specimen geometry and size (Yuan and Brocks, 1998).Therefore, non-standard test specimen (such as single-edge notched tensile ( $\mathrm{SE}(\mathrm{T})$ ) specimen) is also used to determine the fracture toughness property (Dodds et al., 1997). Tyson et al. reported that the actual specimen constraints ae not plane strain, but rather something between plane strain and plane stress. However, in the present study, the estimation of the apparent fracture toughness properties from the quasi-cleavage fractured specimens under plane stress assumption is used to assess the influence of dissolved hydrogen on fracture toughness properties qualitatively. The results clearly showed that dissolved hydrogen can reduce the fracture toughness properties drastically.

\subsubsection{Diffusion of hydrogen}

As mentioned in section 2.1 that during in-situ tensile testing, the specimens were kept in the applied displacement for about 1200 seconds (900 seconds for aging in order to suppress the occurrence of blurring and each scan takes around 300 seconds). Subsequently, the influence of diffusible hydrogen is investigated by ex-situ tensile test with different holding time. The holding time applied was 0, 120, 540 and 2100 seconds, respectively. Fracture surfaces of all the failed specimens were observed in detail under SEM and the quasi-cleavage fracture ratio (QCFR) i.e. the ratio of quasi-cleavage area to the total fracture surface area was measured.

In the present study, we could not use extensometer to measure the actual deformation of the specimens used for ex-situ testing due to their small dimensions. Therefore, the actual 
deformation of the specimen is calculated by subtracting the displacement of the testing fixture from the total displacement recorded by the tensile machine. Under the assumption that the specimen and the testing fixture during tensile testing can be modeled as the elongation of springs connected in series, the displacement recorded by the tensile machine is the sum of the actual deformation of the specimen and the displacement of the loading system, as represented by Eq. (3) (Kalidindi et al. 1996):

$\delta_{T}=\delta_{S}+\delta_{C}$

where, $\delta_{T}$ is the total displacement recorded by the tensile machine, $\delta_{S}$ is the specimen deformation and $\delta_{C}$ is the displacement in the loading system, i.e., the machine compliance. In the present study, the actual change in the specimen length is calculated from the physical displacement of two particles during the in-situ tensile testing. Therefore, the difference between the total displacement recorded by the tensile machine and the actual change in specimen length gives the displacement in the loading system. Finally, the compliance function $\left(\delta_{C}\right)$ of the tensile test machine is determined by plotting the machine compliance-force ( $\delta_{C}$ vs. $F$ ) diagram. The machine compliance vs. applied force diagram is shown in Fig. 13. The compliance function of the tensile test machine obtained from Fig. 13 is:

$\delta_{C}=6.4 \times 10^{-4}\left(\frac{m m}{N}\right) \times F(N)-1.80 \times 10^{-5} \quad 200 \leq \mathrm{F}$

By using the compliance function obtained in Eq. (4), the apparent fracture strain has been calculated. The relationship of QCFR and the estimated fracture strain with holding time is shown in Fig. 14. With increasing holding time, a gradual increase in QCFR (Fig. 14a) and a corresponding decrease in the apparent fracture strain (Fig. 14b) has been observed. It is interesting to note that specimens with holding time $0 \mathrm{~s}$ and $120 \mathrm{~s}$, respectively showed almost zero QCFR, with ductile fracture mode. The quasi-cleavage feature becomes dominant with 540s 
holding specimens. This clearly indicated the existence of a threshold concentration of hydrogen ahead of the crack tip for the nucleation of quasi-cleavage feature.

\subsubsection{Estimation of hydrogen trapped at each trap sites}

The $2 \mathrm{D}$ equivalent strain distribution ahead of the crack tip is shown in Fig. 15. The strain mapping was carried out with equivalent strain ranging from 0 to $30 \%$, and the crack is indicated with white in Fig. 15. A very high strain distribution ahead of the crack tip is observed. The combined effect of tensile stress and high concentration of hydrogen ahead of the crack tip might have increased the strain resulting a local decrease in flow stress and facilitate the localization of slip process.

The trapping sites of this excess hydrogen induced by EDM wire eroder needs to be understood. In the case of aluminum alloys solute atoms, lattice interstices, dislocations, vacancies, precipitates, high angle grain boundaries act as hydrogen trap sites (Smith and Scully 2003). According to Oriani's theory (1970), hydrogen stored in normal interstitial lattices and other traps sites should be in equilibrium, as shown in Eq. (5):

$\frac{\theta_{T}}{1-\theta_{T}}=\theta_{L} \exp \left(\frac{E_{b}}{R T}\right)$

where $E_{b}$ is the trap binding energy, $R$ is the gas constant equal to $8.31 \mathrm{~J}^{\text {mole }}{ }^{-1} \mathrm{~K}^{-1}, T$ is the absolute temperature, $\theta_{L}$ and $\theta_{T}$ are the occupancy of the interstitial sites and trap sites, respectively. Total hydrogen concentration, $C_{H}^{T}$, represents the sum of the hydrogen stored in a normal interstitial lattice and all trap sites, corresponding to the total hydrogen content listed in Table 3:

$C_{H}^{T}=\theta_{L} N_{L}+\sum \theta_{T i} N_{T i}+C_{\text {pore }}$

where $N_{L}$ and $N_{T i}$ are trap densities in the normal interstitial lattice and $\mathrm{i}^{\text {th }}$ trap sites other than micropores in atoms per unit volume, respectively. $C_{\text {pore }}$ represents total hydrogen atoms per 
unit volume trapped in micropores, corresponding to the hydrogen in micropores $\left(\mathrm{M}_{\mathrm{H} \text { pore }}\right)$ listed in Table 3.

In this analysis trap binding energy, $E_{b}$ for solute magnesium was assumed to its upper limit, i.e. $5.8 \mathrm{~kJ} \mathrm{~mol}^{-1}$ (Leger and Piercy 1981) and $E_{b}$ values for the interstitial lattice, dislocation, high angle grain boundaries, and vacancies are 0, 31, $35 \mathrm{~kJ} \mathrm{~mol}^{-1}$ (Smith and Scully 2003), and 20 $\mathrm{kJmol}^{-1}$ (Izumi and Itoh 2011), respectively. Dislocation density is taken from Bhuiyan et al. Trap site occupancy and the concentration of hydrogen for each trap site is listed in Table 4. For comparison, the result of estimated trap site coverage of material MH is also shown in Table 4. Though the total amounts of hydrogen trapped in micropores are same in both materials, but the trap site occupancy values for the vacancy, dislocation and grain boundaries in MH_EDM material is dramatically elevated. In fact, the trap site occupancy is increased by a factor of 672.5 for vacancy, 152 for dislocation, and 6.21 for grain boundaries.

\subsubsection{Relationship between crack tip hydrogen concentration and quasi-cleavage fracture}

Specimens with $1.5 \mathrm{~mm}$ (width, W), and $1.5 \mathrm{~mm}$ (thickness, T) and 22 (length, L) $\mathrm{mm}$ ) were machined using an electro-discharge machine (EDM) wire eroder and then polished in width and thickness direction until the specimen size reduces to 0.6 (width, W), 0.6 (thickness, T). Hereinafter, the specimens were called as polished material $\mathrm{LH}$, polished material $\mathrm{MH}$, and polished material $\mathrm{HH}$, respectively. Since $450 \mu \mathrm{m}$ was removed from each side of all the polished specimens, therefore, it is speculated that the polished specimens will be free from diffusible hydrogen induced by EDM wire eroder. The results of in-situ tensile tests also showed quasi-cleavage feature near specimen surface, and ductile with typical dimples at the interior, even though the surface area containing EDM wire eroder induced hydrogen has been removed. 
This suggests that the critical behavior of hydrogen associated with the quasi-cleavage crack initiation might be related with the plastic strain and increased hydrogen concentration.

The hydrogen content for each material near crack tip is measured assuming that hydrogen atoms are transported by dislocations. The dislocation density of fractured specimen is determined by XRD peak profile analysis according to the modified Williamson-Hall method. An automated diffractometer using $\mathrm{Cu}-\mathrm{K} \alpha$ radiation operating at $40 \mathrm{kV}$ and $30 \mathrm{~mA}$ with wavelength of 0.154 $\mathrm{nm}$ was used for XRD. The samples were scanned continuously over a range of $2 \theta$ from 30 to $130 \mathrm{deg}$ at a scan rate of $0.02 \mathrm{deg} / \mathrm{min}$. From the XRD data, the value of full width at halfmaximum (FWHM) is calculated and substituted into the modified Williamson-Hall equation. The procedure is reported elsewhere (Bhuiyan et al. 2015). The dislocation density of fractured specimen was estimated to be $3.06 \times 10^{17} \mathrm{~m}^{-2}$.

Assuming that one hydrogen atom is threaded with each dislocation, the trap density due to dislocation $\left(N_{T D}\right)$ is calculated. Therefore, the trapped hydrogen due to dislocation, $C_{H}^{D}$ is:

$C_{H}^{D}=\theta_{T D} N_{T D}$

where $N_{T D}$ is the trap density due to dislocation and $\theta_{T D}$ is the trap site occupancy for dislocation.

The trapped hydrogen ahead of the crack tip, $C_{H}^{\text {Plastic zone }}$, is:

$C_{H}^{\text {plastic zone }}=V_{\text {Dislocation }} \times\left(C_{H}^{N I L S}+C_{H}^{\text {Solute } M g}+C_{H}^{V}+C_{H}^{D}+C_{H}^{G B}\right)$

where, $V_{\text {Dislocation }}$ is the volume of the high density dislocation region $\left(V_{\text {Dislocation }}=\right.$ Projected area of corner crack $\times$ height of crack wake), $C_{H}^{N I L S}$ is the trapped hydrogen at interstitial lattice, $C_{H}^{\text {Solute } M g}$ is hydrogen trapped at solute atoms, $C_{H}^{V}$ is the hydrogen trapped at vacancies, $C_{H}^{D}$ is the hydrogen tapped at dislocation and can be obtained by using Eq. (7), $C_{H}^{G B}$ is the hydrogen trapped at grain boundaries. 
The hydrogen content for each material near crack tip is evaluated by using Eq.(7) and Eq. (8) and is shown in Table 5. The total hydrogen content is also shown in Table 5. It is interesting to note that the hydrogen concentration ahead of the crack tip increases for all the materials. Compared to the initial hydrogen content (i.e. before deformation state) the crack tip hydrogen concentration increased by 989 times for material $\mathrm{HH}, 853$ times for material MH, and 584 times for material LH, respectively. Interestingly, material MH_EDM showed only 170 times higher hydrogen concentration near the crack tip. In fact, before deformation state the material MH_EDM showed quite high hydrogen concentration. Therefore, during deformation, the increasing amount of hydrogen with increased dislocation becomes relatively small. However, Ohnishi and Higashi (1984) reported that extremely high concentration of hydrogen can be induced within the plastic zone and could reach 1000 times compared to that of before deformation, which is consistent with our experimental results.

The relationship between the quasi-cleavage fracture ratio (QCFR) and the hydrogen concentration ahead of the crack tip is shown in Fig. 17. A linear relationship between QCFR and crack tip hydrogen concentration has been observed. The intercept of the line with the total hydrogen concentration axis gives the optimum value of about $13 \mathrm{ml} / 100 \mathrm{gAl}$, below which quasi-cleavage fracture will not occur. Therefore, it can be concluded when crack tip hydrogen concentration is less than or equal to $13 \mathrm{ml} / 100 \mathrm{gAl}$, then it is speculated that quasi-cleavage fracture will not dominate the fracture.

\section{Discussion}

Two major observations made in the present study are: (i) hydrogen susceptibility of Al-Zn-Mg$\mathrm{Cu}$ series alloys increased with increased $\mathrm{Zn}$ addition, (ii) the increased quasi-cleavage area with increased holding time clearly indicated that quasi-cleavage fracture is time dependent 
phenomena. Hydrogen assisted fracture is mainly dominated by hydrogen transport, which could be achievable either by the diffusive process or by dislocation transportation mechanism. Since the diffusivity of hydrogen in aluminum is very low, Albrecht et al. (1979) argued that hydrogen atoms are transported by dislocations. Bond et al. (1987) observed the existence of dense dislocation tangles ahead of the crack tip and reported that dislocation mobility was enhanced by hydrogen. Further evidence of hydrogen-dislocation interaction has been provided by Lu and coworkers (2001). They reported that the presence of hydrogen not only enhanced the mobility of screw, edge and mixed dislocation in aluminum but also facilitates dislocation emission from crack tip. Since hydrogen is transported with the dislocations, high hydrogen concentrations should exist in regions of high dislocation density, especially ahead of the crack tip. Hence, the plastic zone size ahead of the crack tip will be greater, which is consistent with the evidence presented in Fig. 10. . Therefore, it can be concluded that the HELP model is a more applicable mechanism of hydrogen embrittlement of the present alloys.

\section{Conclusion}

Synchrotron X-ray microtomography was used to observe the influence of both hydrogen micropores and dissolved hydrogen during deformation and fracture in a high Zn 7XXX aluminum alloys. We have clarified that the hydrogen susceptibility has drastically increased with increasing the $\mathrm{Zn}$ amount. High concentration of hydrogen was induced by the EDM wire eroder, which induces quasi-cleavage fracture and restricts the growth of micropores during ductile deformation. Based on the interrupted ex-situ tensile test we found that a critical concentration of hydrogen in required for nucleating the quasi-cleavage feature and its value is estimated to be less than or equal to $13 \mathrm{~cm}^{3} / 100 \mathrm{~g} \mathrm{Al}$.

\section{Acknowledgement}


The synchrotron radiation experiments were performed with the approval of JASRI through proposal No.2013B1324, 2014A1018, and 2014B1157. This work was undertaken as a part of Development of Innovative Aluminum Materials Projects and Technological Development of Innovative New Structural Materials with the project code HAJJ262715.

\section{References}

Adler PN, De lasi R, Geschwind G. Influence of Microstructure on the Mechanical Properties and Stress Corrosion Susceptibility of 7075 Aluminum Alloys. Metallurgical Transactions 1971; 3: $3191-3200$

Albrecht J, Thompson AW, Bernstein IM. The Role of Microstructure in Hydrogen-Assisted Fracture of 7075 Aluminum. Metallurgical Transaction 1979; 10A: 1759-1766.

Ambat R, Dwarakadasa ES. Effect of hydrogen in aluminum and aluminum alloys: A review. Bulletin of Materials Science 1990; 19 (1): 103-114

Balasubramaniam R, Duquette DJ, Rajan K. On the stress corrosion cracking in AluminumLithium alloys. Acta Materialia 1991; 39 (11): 2597-2605

Tyson B, Ding P, Wang X. Elastic compliance of single-edge-notched tension SE(T) (or SENT) specimens. Fratturaed Integrità Strutturale 2014; 30: 95-100

Bhuiyan MS, Peng Z, Hang S, Toda H, Uesugi K, Takeuchi A, Suzuki Y, Sakaguchi N, Watanabe Y. Combined microtomography, thermal desorption spectroscopy, X-ray diffraction study of hydrogen trapping behavior in $7 \mathrm{XXX}$ aluminum alloys. Materials Science and Engineering A (accepted)

Bond GM, Robertson IM, Birbaum HK. The influence of hydrogen on deformation and fracture process in high strength aluminum alloys. Acta Materialia 1987; 35 (9): 2289-2296 
Barber CB, Dobkin DP, Huhdanpaa HT. The Quickhull Algorithm for Convex Hulls. ACM Transactions on Mathematical Software 1996; 22: 469-483

BS 7910. Guidance on Methods for Assessing the Acceptability of Flaws in Fusion Welded Structures, London, British Standards Institution (BSI), 2000

Chen Z, Mo Y, Nie Z. Effect of Zn content on the microstructure and properties of Super-High Strength Al-Zn-Mg-Cu Alloys. Metallurgical and Materials Transactions A 2013; 44A: 39103920

Dodds RH, Ruggieri C, Koppenhoefer K. 3-D Constraint Effects on Models for Transferability of Cleavage Fracture Toughness. ASTM Special Technical Publication 1997; 1321: 179-197 Gest RJ, Troiano AR. Stress Corrosion and Hydrogen Embrittlement in an Aluminum Alloys. Corrosion 1974; 30 (8): 274-279

Gruhl W, Metallkd Z. Stress corrosion cracking of high strength Aluminum alloys. Materials Science Engineering A 1984; 75 (11): 819-826

Holroyd NJH, Hardie D. Strain-rate effects on the environmentally assisted fracture of a commercial high-strength aluminum alloys (7049). Corrosion Science 1981;21:129-144 Hardie D, Holroyd N J H, Parkins R N. Reduced ductility of high-strength aluminum alloy during or after exposure to water. Metal Science 1979; 13 (11): 603-610

Immarigeon JP, Holt RT, Koul AK, Zhao L, Wallace W, Beddos JC. Lightweight Materials for Aircraft Applications. Materials Characterization 1995; 35: 41-67

Izumi T, Itoh G. Thermal Desorption Spectroscopy Study on the Hydrogen Trapping States in a Pure Aluminum. Materials Transactions 2011; 52 (2): 130-134

Imabayashi M, Tomita K. Method for measuring hydrogen in aluminum by vacuum fusion extraction. Journal of Japan Institute of Light Metals 2014; 22(1): 73-81 
Koyama K. High-Strength and Heat Resistant Aluminum Alloys. Furukawa-Sky Review 2010;

6: 7-22

Koyama M, Akiyama E, Sawaguchi T, Ogawa K, Kireeva I V, Chamlyakov Y I, Tsuzaki K. Hydrogen-assisted quasi-cleavage fracture in a single crystalline type 316 austenitic stainless steel. Corrosion Science 2013; 75: 345-353

Kalidindi SR, Abusafieh A, El-Danaf E. Accurate Characterization of Machine Compliance for Simple Compression Testing. Experimental Mechanics 1996; 37 (2): 210-215.

Kamoutsi H, Haidemenopoulos G N, Bontozoglou V, Pantelekis S. Corrosion-induced hydrogen embrittlement in aluminum alloy 2024. Corrosion Science 2006; 48: 1209-1224

Kobayashi M, Toda H, Kawai Y, Ohgaki T, Uesugi K, Wilkinson DS, Kobayashi T, Aoki Y, Nakazawa M. High-density three-dimensional mapping of internal strain by tracking microsctural features. Acta Materialia 2008; 56: 2167-2181

Leger M, Piercy GR. Internal friction in hydrogen-charged aluminum alloys. Philosophical Magazine A 1981; 43: 377-385

Lu G, Zhang Q, Kioussis N, Kaxiras E. Hydrogen-Enhanced Local Plasticity in Aluminum: An Ab Initio Study. Physical Review Letters 2001; 87 (9): 095501-1-095501-4

Milman YV, Sirko A I, Lotsko D V, Senkov O N, Miracle D B. Microstructure and Mechanical Properties of Cast and Wrought Al-Zn-Mg-Cu Alloys Modified with Zr and Sc. Materials Science Forum 2002; 396-402: 1217-1222.

Meletis EI, Huang W. The role of the T1 phase in the pre-exposure and hydrogen embrittlement of Al-Li-Cu Alloys. Materials Science and Engineering A 1991; 148: 197-209 Nguyen D, Thompson AW, Bernstein IM. Microstructural effects on hydrogen embrittlement in a high purity 7075 aluminum alloys. Acta Materialia 1987; 35 (10): 2417-2425 
Ohinishi T, Higashi K. Application of fracture mechanics to propagation of stress corrosion crack based on localized hydrogen embrittlement. Light Metal 1984; 34 (12): 675-681

Oriani RA. The diffusion and trapping of hydrogen in steel. Acta Materialia 1970; 18: 147-157

Park JK, Ardell AJ. Effect of retrogression and reaging treatments on the microstructure of Al7075-T651.Metallurgical Transactions 1984; 15A: 1531-1543

Pickens JR, Gordon JR, Green AS. The Effect of Loading Mode on the Stress-Corrosion Cracking of Aluminum alloys 5083. Metallurgical Transactions 1983; 14A: 925-930

Rometsch PA, Zhang Y, Knight S. Heat treatment of 7XXX series aluminum alloys-Some recent developments. Transaction of Nonferrous Metals Society of China 2014; 24: 2003-2017 Seyed Ebrahimi SH, Emamy M, Pourkia N, Lashgari HR. The microstructure, hardness and tensile properties of a new super high strength aluminum alloys with $\mathrm{Zr}$ addition. Materials Design 2010; 31: 4450-4456

Smith S W, Scally J R. The Identification of Hydrogen Trapping States in an Al-Li-Cu-Zr Alloys Using Thermal Desorption Spectroscopy. Metallurgical and Materials Transaction a 2003; 31A: $179-183$

Starke EA Jr., Staleyt JT. Application of modern aluminum alloys to aircraft. Progress in Aerospace Sciences 1996; 32 (2-3): 131-172

Taheri M. Albrecht J, Bernstein IM, Thompson AW. Strain-rate Effects on Hydrogen Embrittlement of 7075 Aluminum. Scripta Metellurgica 1979; 13: 871-875

Takano N. Hydrogen diffusion and embrittlement in 7075 aluminum alloys. Materials Science and Engineering A 2008; 483-484: 336-339

Thakur C, Balasubramaniam R. Hydrogen embrittlement of aged and retrogressed reaged Al-LiCu-Mg alloys. Acta Metallurgical 1997; 45 (4): 1323-1332 
Thompson AW, Bernstein IM. Environmental Fracture of Aluminum Alloys and Stainless Steels as a Function of Composition and Microstructure. Reviews on Coating \& Corrosion 1975; 2: 344

Thompson AW, Bernstein IM. The Role of Metallurgical Variable in Hydrogen Assisted Environmental Fracture. Advances in Corrosion Science and Technology, Fontana MG and Staehle RW eds. NewYork 1980; 7: 53-175

Toda H, Marie E, Aoki Y, Kobayashi M. Three-dimensional strain mapping using in situ X-ray shynchrotron microtomography. The Journal of Strain Analysis for Engineering Design 2011; 46: $549-561$

Toda H, Inamori T, Horikawa K, Uesugi K, Takeuchi A, Suzuki Y, Kobayashi M. Effects of Hydrogen Micro Pores on Mechanical Properties in A2024 Aluminum Alloys. Materials Transactions 2013; 54 (12): 2195-2201

Toda H, Inamori T, Horikawa K, Uesugi K, Takeuchi A, Suzuki Y, Kobayashi M. Effects of Hydrogen Micro Pores on Mechanical Properties in A2024 Aluminum Alloys. Materials Transactions 2013; 54 (12): 2195-2201

Toda H, Oogo H, Horikawa K, Uesugi K, Takeuchi A, Suzuki Y, Nakazawa M, Aoki Y, Kobayashi M. The True Origin of Ductile Fracture in Aluminum Alloys. Metallurgical and Materials Transactions A 2014; 45A: 765-776

Toda H, Kobayashi T, Takahasi A. Micromechanisms of fracture in wrought aluminum alloy containing coarse inclusion particles. Aluminum Transactions 1999; 11: 109-116 Truck CDS. The embrittlement of Al-Zn-Mg and Al-Mg Alloys by Water Vapor. Metallurgical Transactions A 1985; 16: 1503-1514 
Ungár T, Borbély A. The effect of dislocation contrast on x-ray line broadening: A new approach to line profile analysis. Applied Physics Letter 1996; 69: 3173-3175.

Woo W, Ungár T, Feng Z, Kenik E, Clausen B. X-Ray and Neutron Diffreaction Measurements of Dislocation Density and Subgrain Size in a Friction-Stir-Welded Aluminum Alloy.

Metallurgical and Materials Transactions A 2010; 41: 1210-1216

Yuan H, Brocks W. Quantification of Constraints Effects in Elastic-Plastic Crack Front Fields.

Journal of the Mechanics and Physics of Solids 1998; 46 (2); 219-241

Zeides F, Roman I. Study of Hydrogen Embrittlement in Aluminum Alloys 2024 in the

Longitudinal Direction. Materials Science and Engineering A 1990; 125: 21-30

Zhao J, Jiang Z, Lee C S. Effects of tungsten on the hydrogen embrittlement behavior of microalloysed steels. Corrosion Science 2014; 82: 380-391

Zhu XK, Joyce JA. Review of fracture toughness (G, K, J, CTOD, CTOA) testing and standardization. Engineering Fracture Mechanics 2012; 85: 1-46 

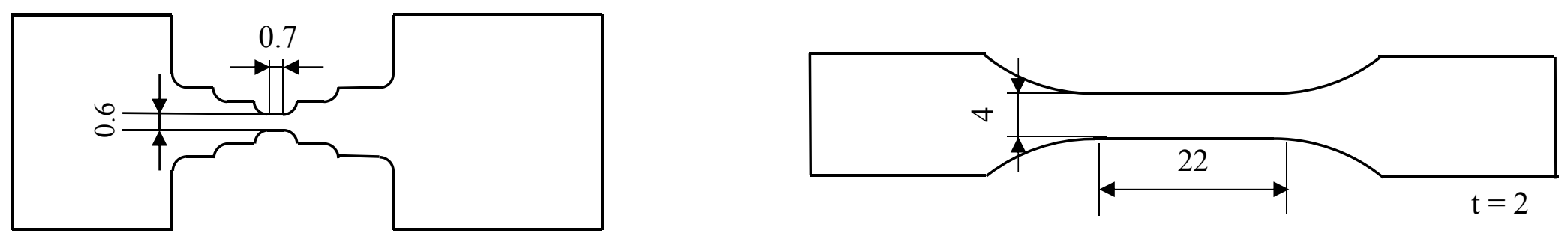

$$
\mathrm{t}=0.6
$$

(a) In-situ tensile test specimen

(b) Smooth specimen for room temperature tensile test

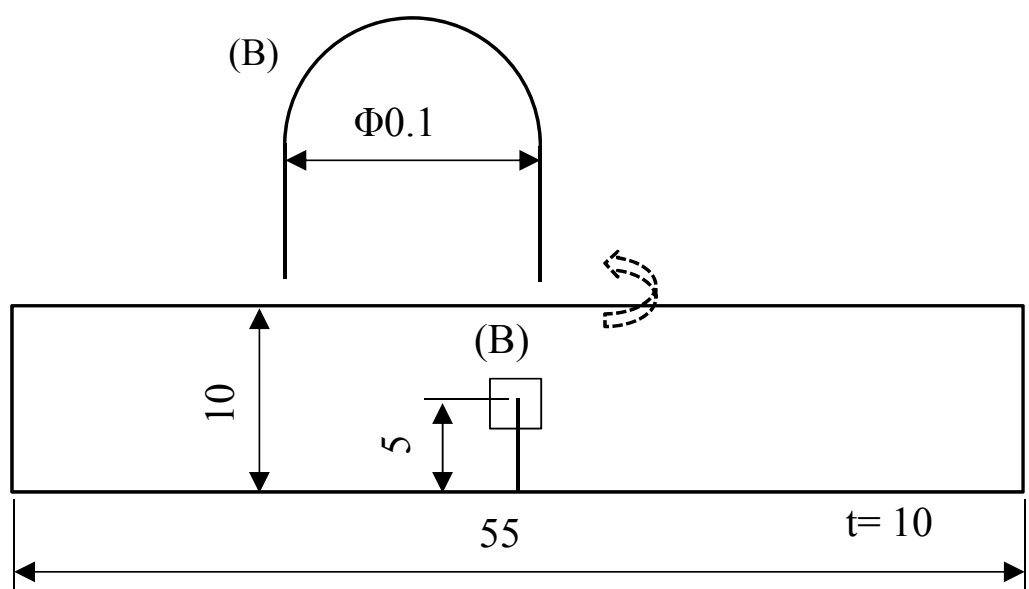

(c) Fracture toughness test specimen

[unit : $\mathrm{mm}$ ]

Fig. 1. Geometries of mechanical test specimens 


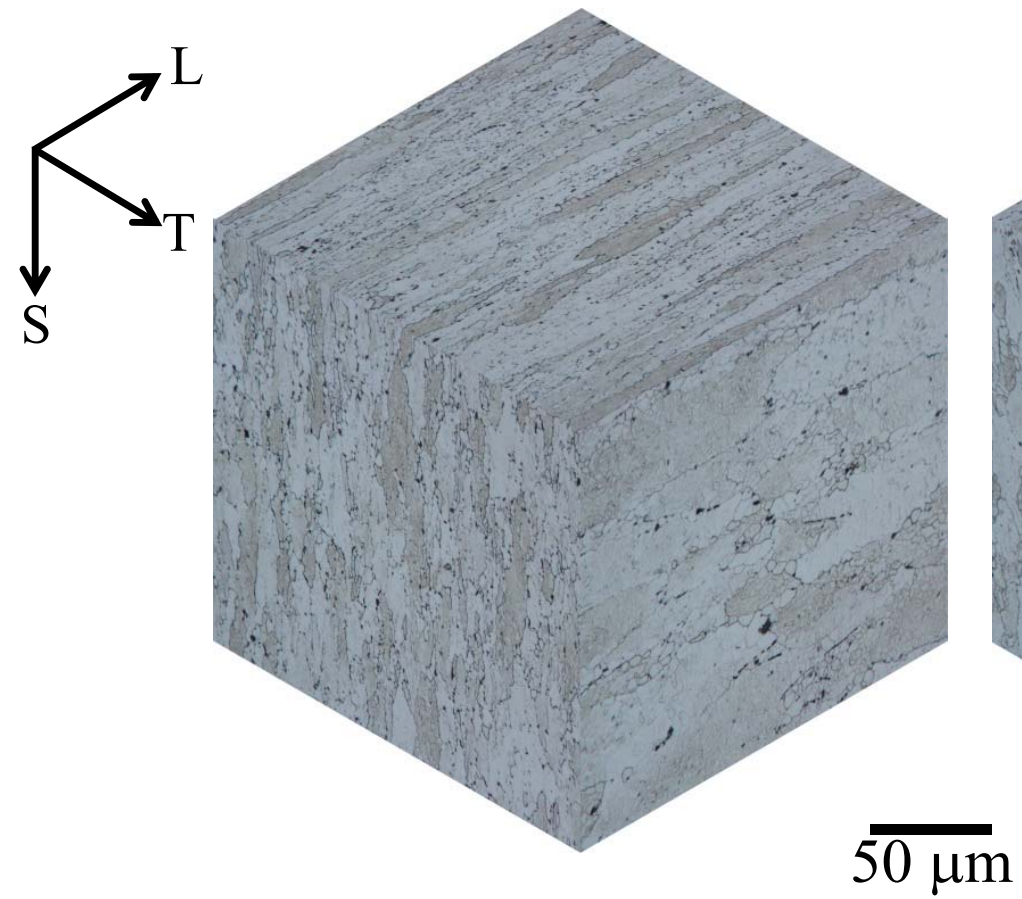

Material LH

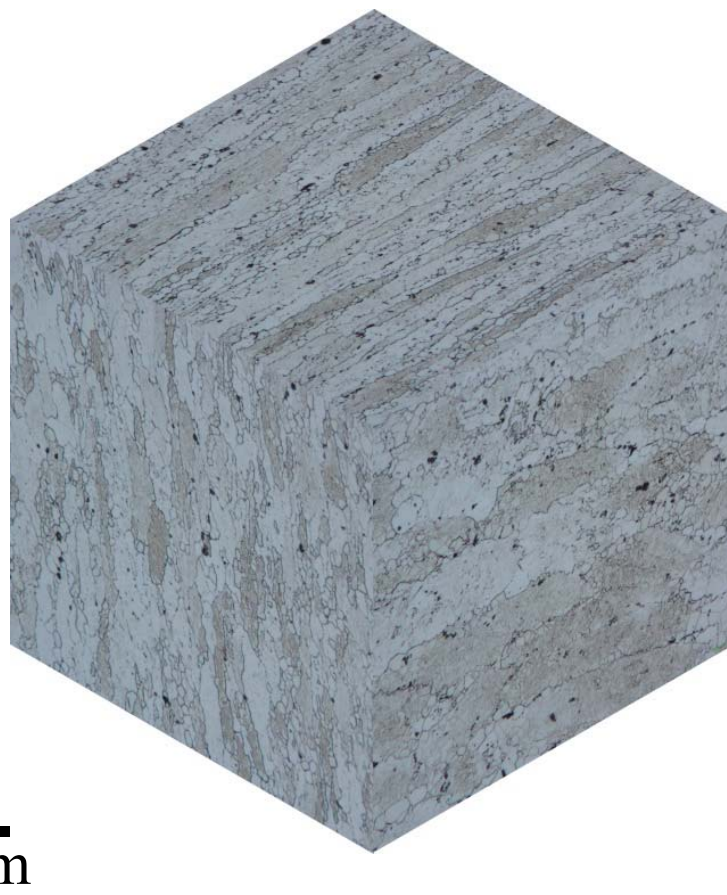

Material MH

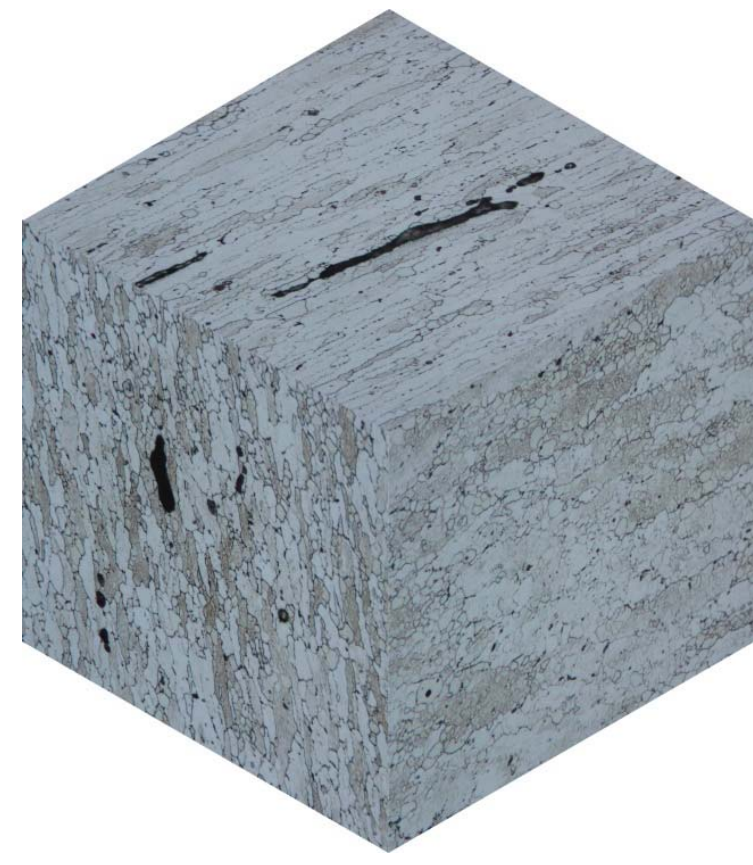

Material HH

Fig. 2. Optical micrograph of the alloys investigated. 
(a)
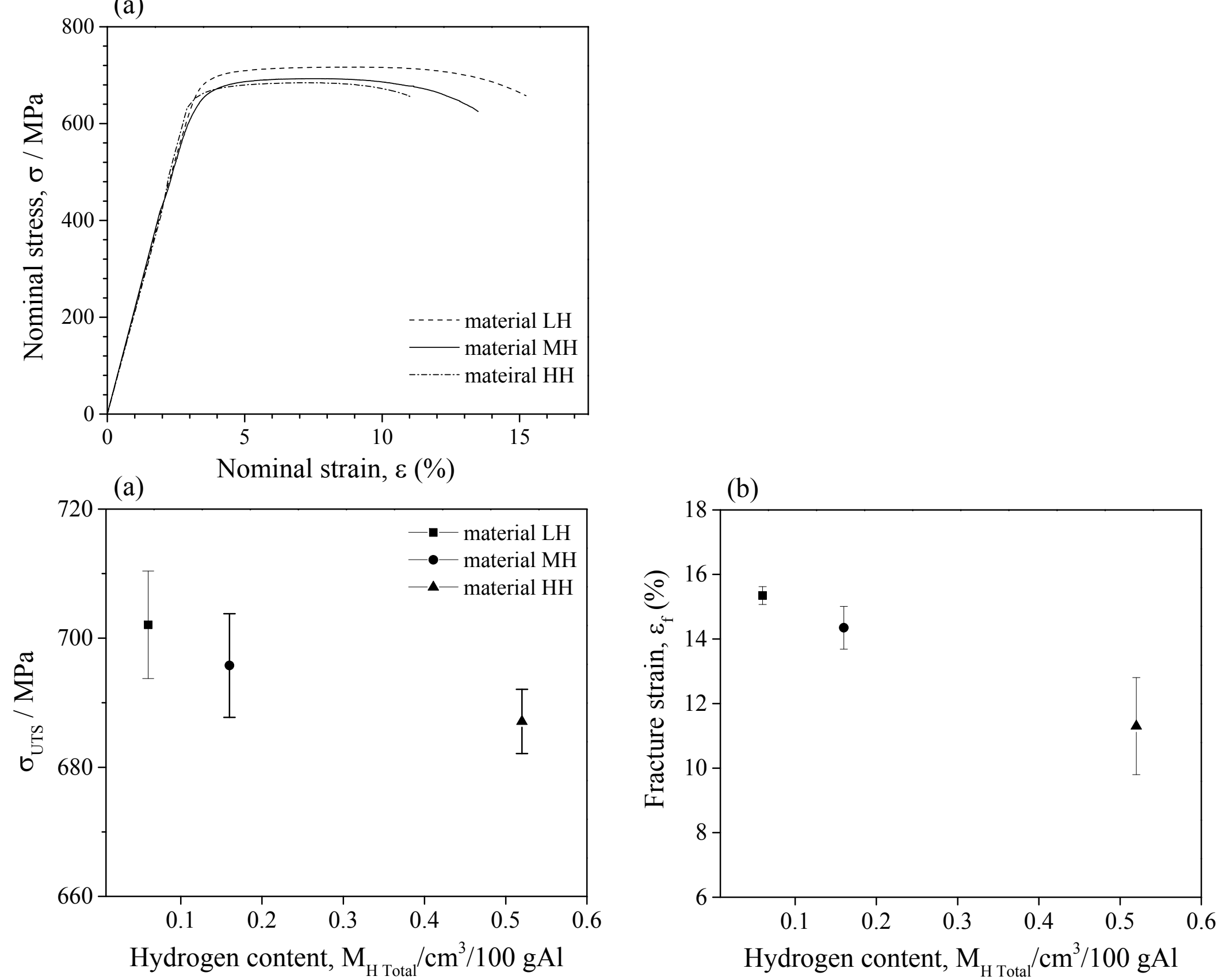

Fig. 3. (a) Typical stress-strain curves obtained in the room temperature tensile tests with smooth specimens. Effect of hydrogen content on: (b) ultimate tensile strength, and (b) fracture strain 

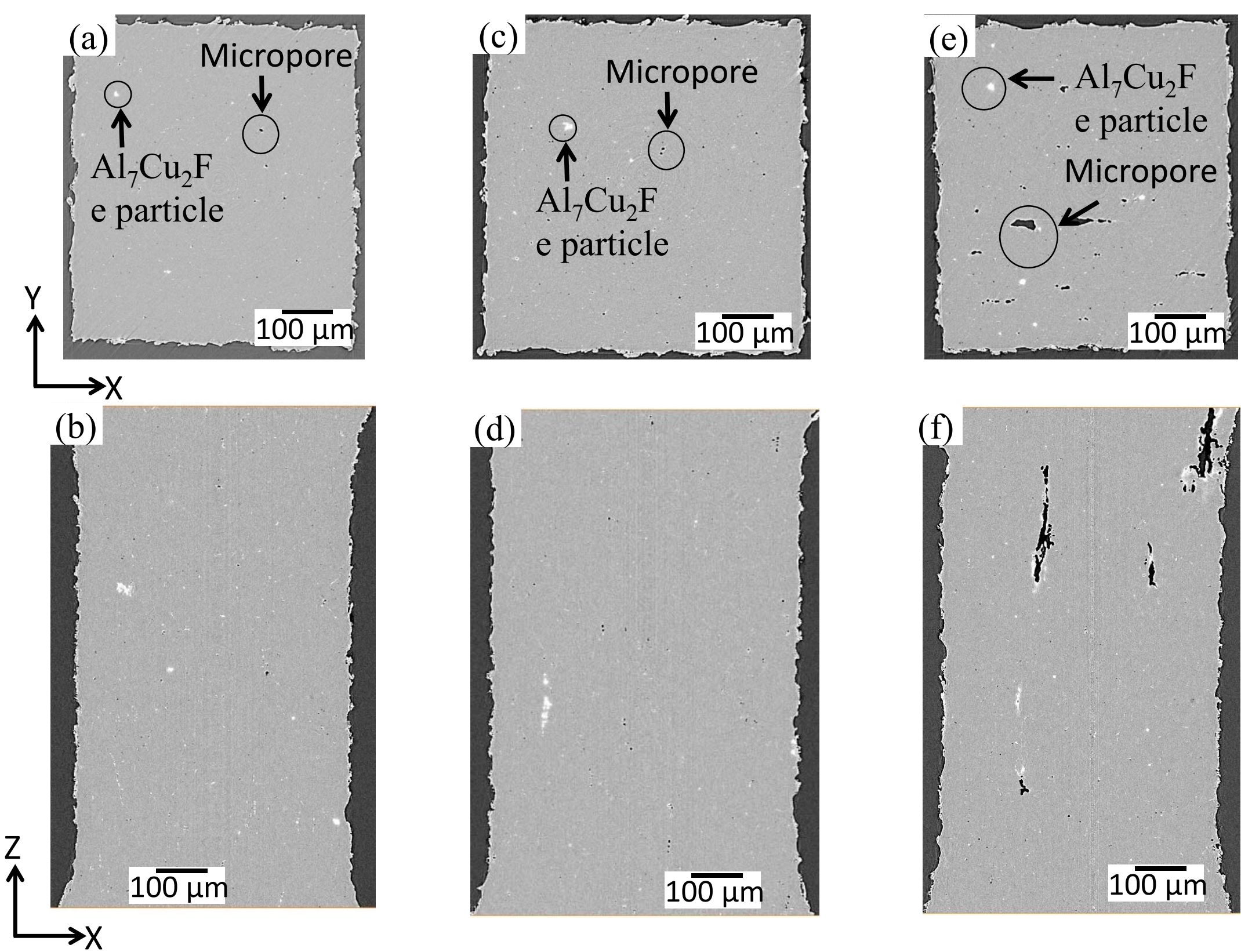

Fig. 4. In-situ 2D radiographs showing typical distribution of micropores (black) and particles (white) in the present 7XXX aluminum alloys. (a) (b) for material LH showing, (c) $\sim$ (d) for material $\mathrm{MH}$, and (e) (f) for material $\mathrm{HH}$. 
(a)

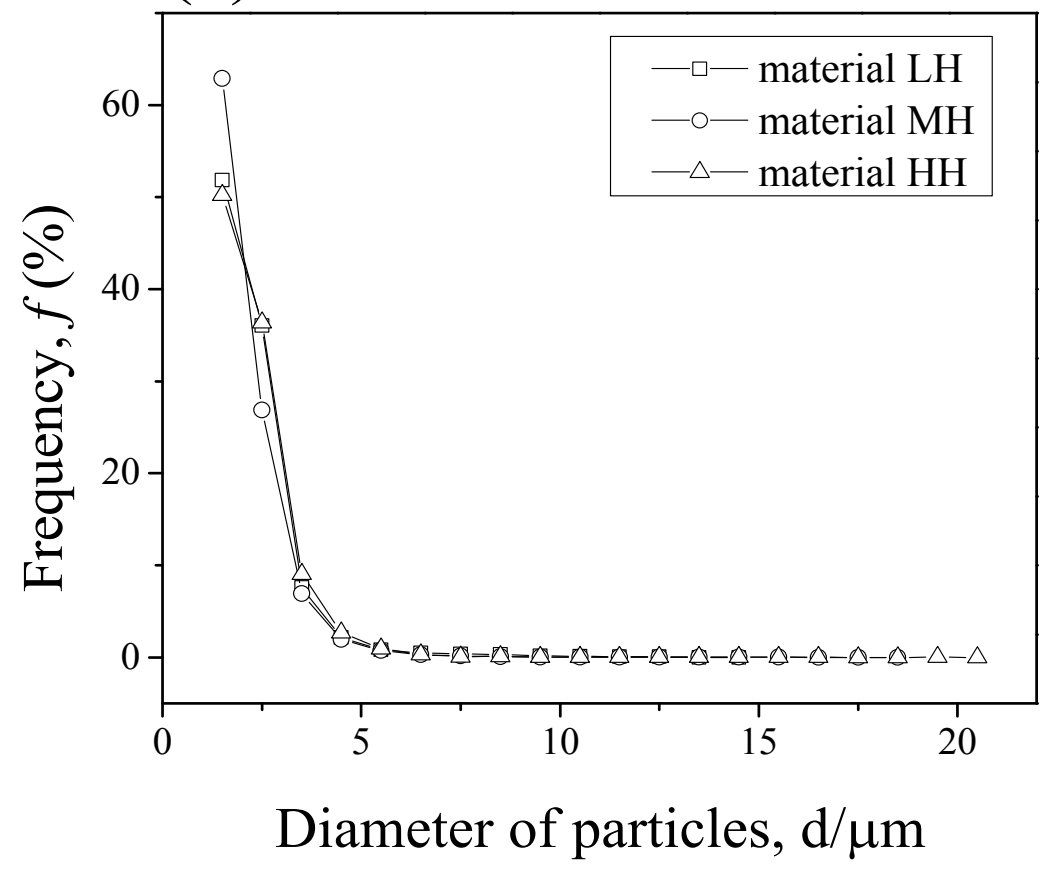

(b)

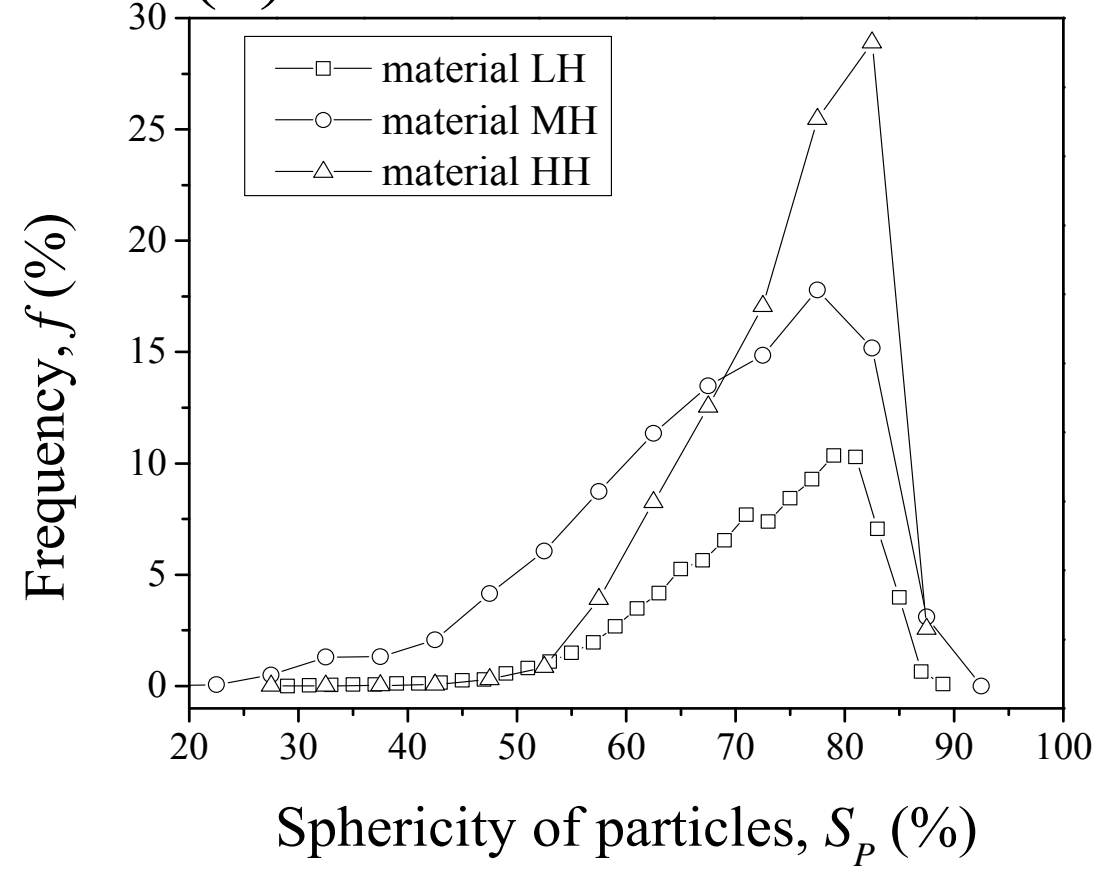

Fig. 5. Variations of diameter and sphericity of particles in material $\mathrm{LH}$, material $\mathrm{MH}$ and material $\mathrm{HH}$. 


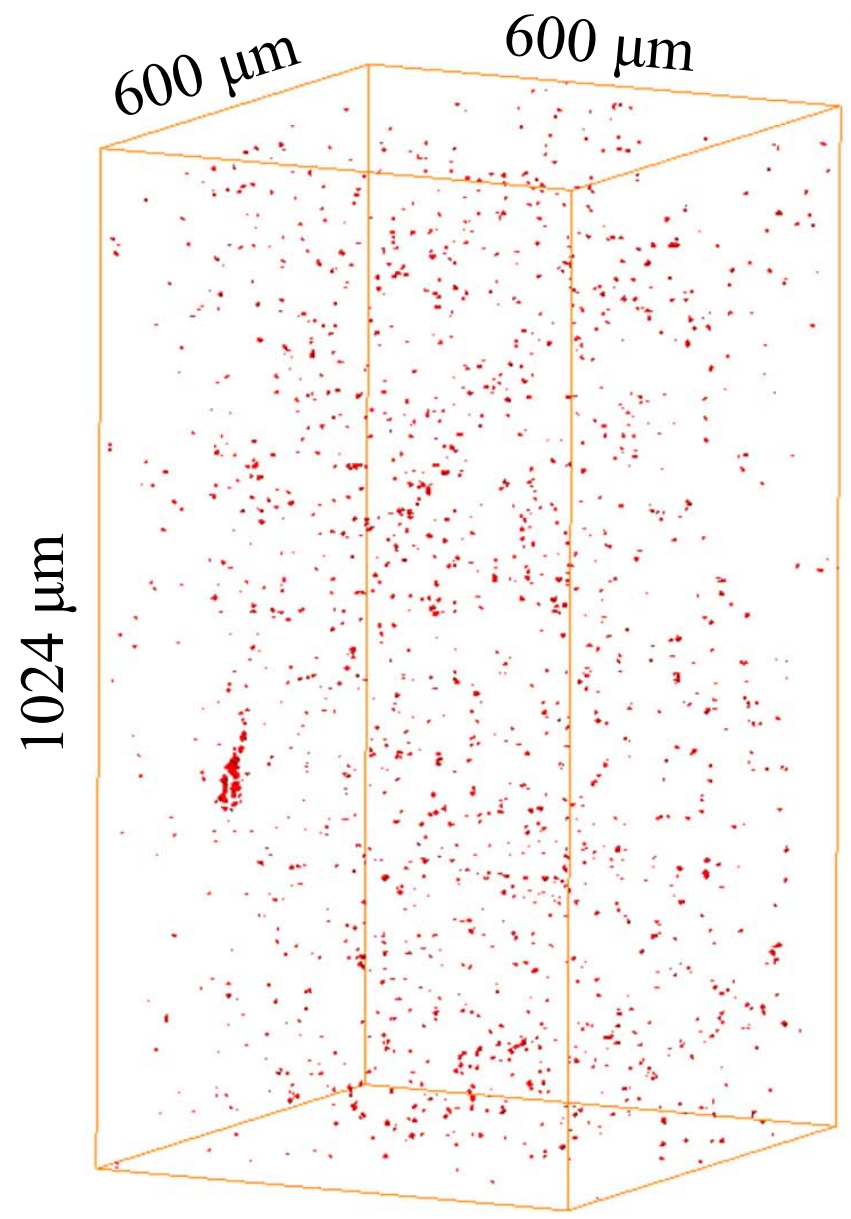

$\mathrm{LH}$

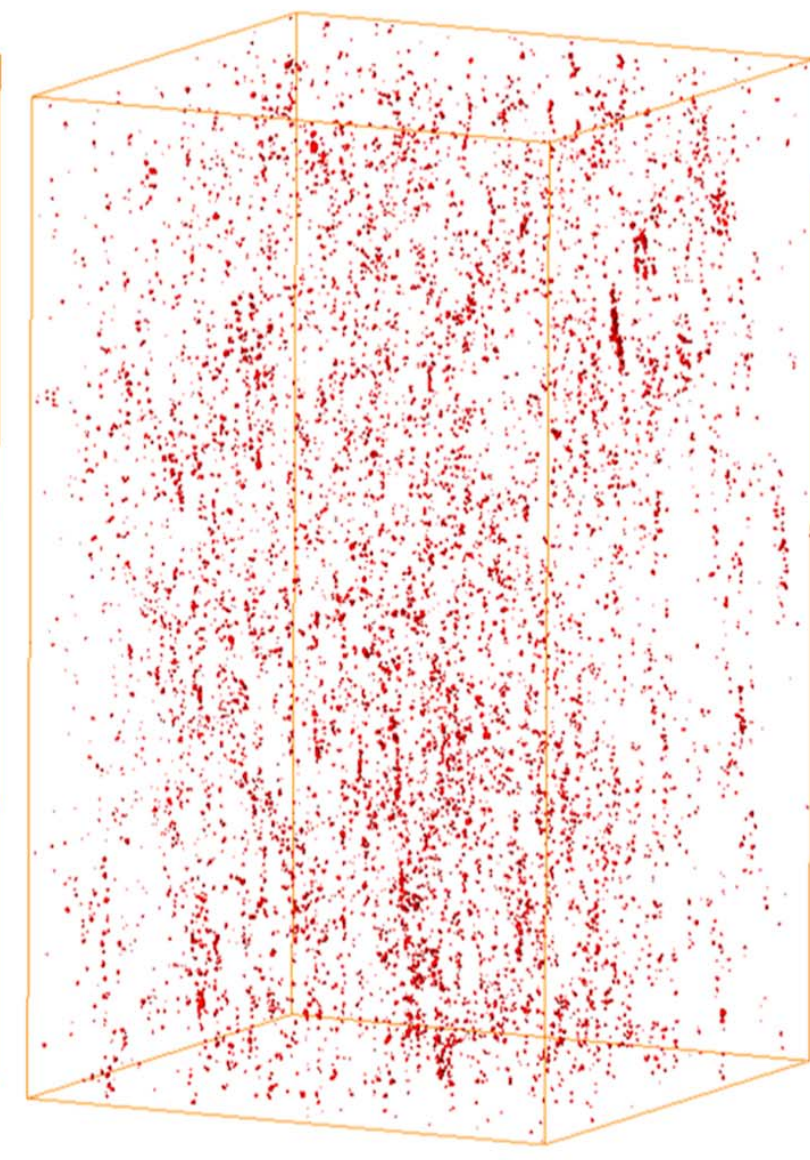

$\mathrm{MH}$

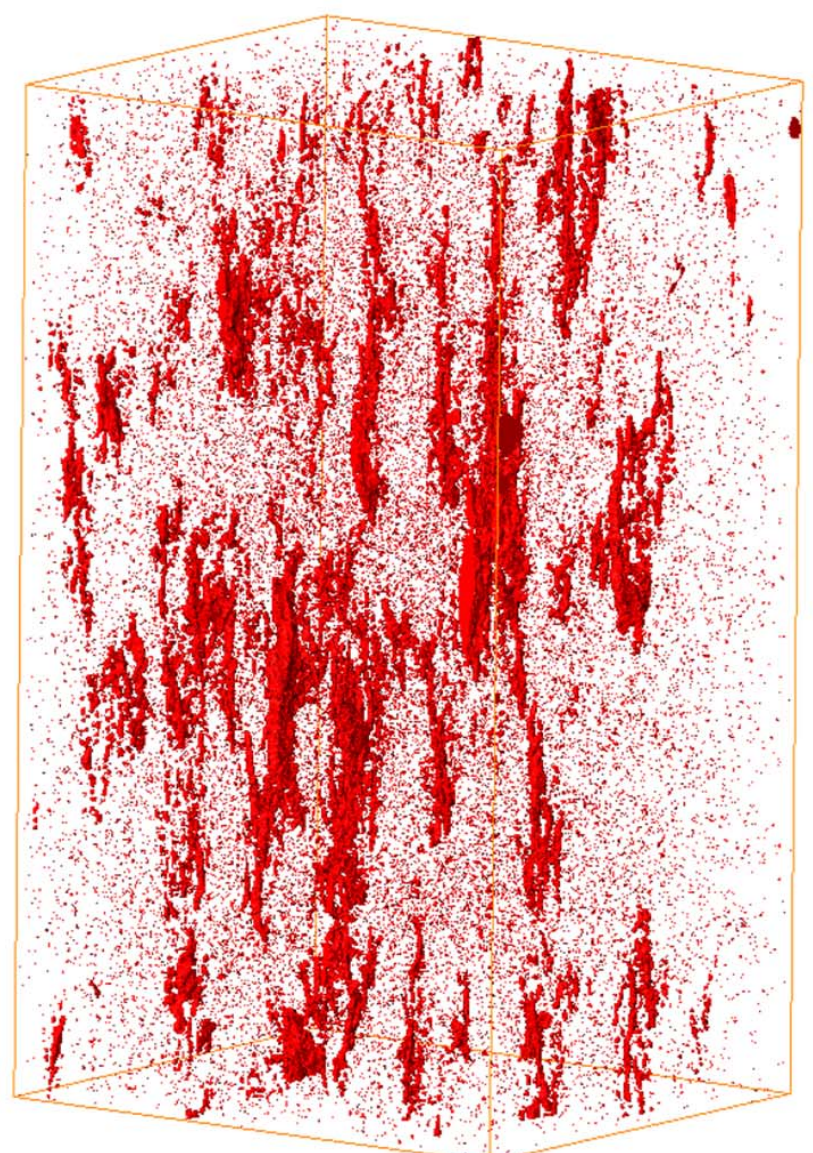

$\mathrm{HH}$

Fig. 6. 3D perspective views of micropores. Only micropores were extracted and shown here, and underlying aluminum is not displayed. 


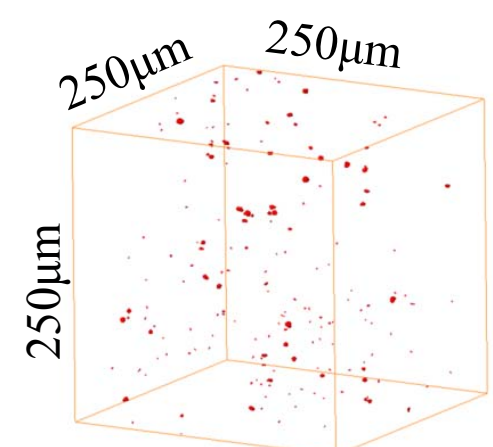

(a) Before loading

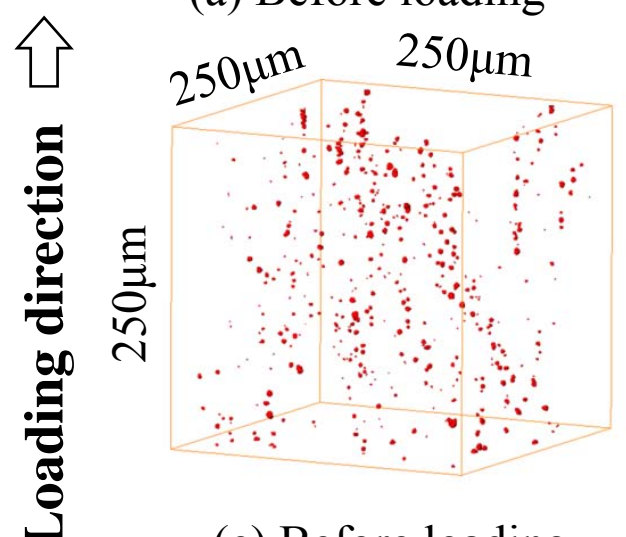

(e) Before loading

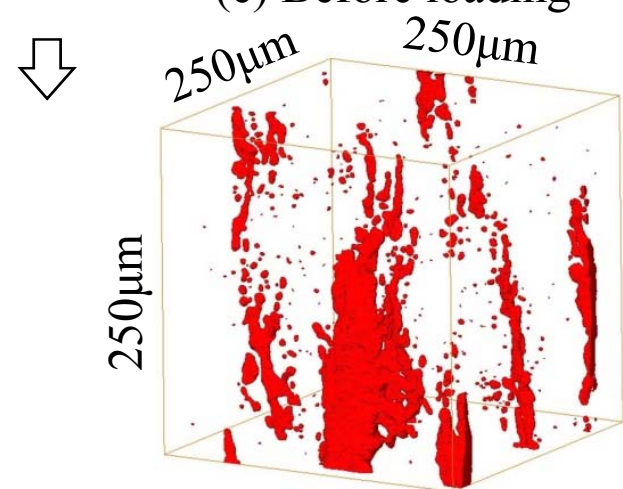

(i) Before loading

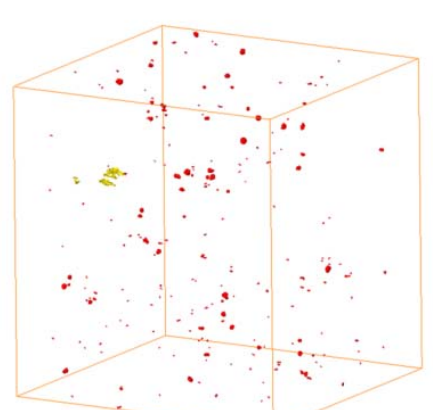

(b) 3rd loading step

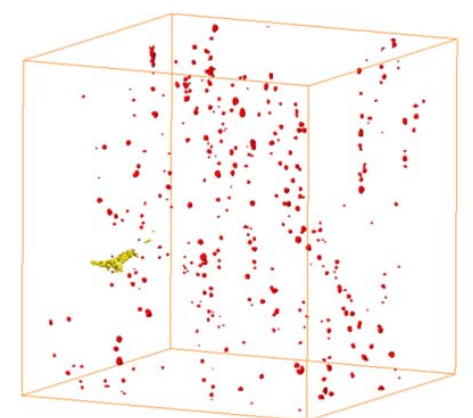

(f) 3rd loading step

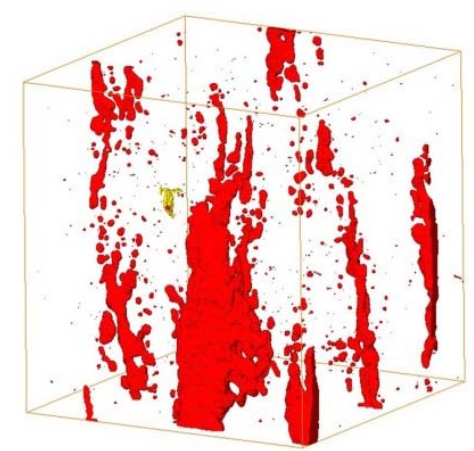

(j) 3rd loading step

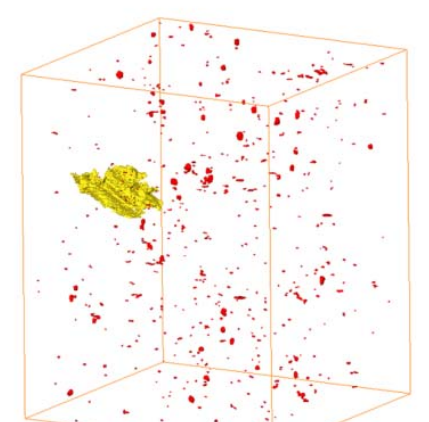

(c) 6th loading step

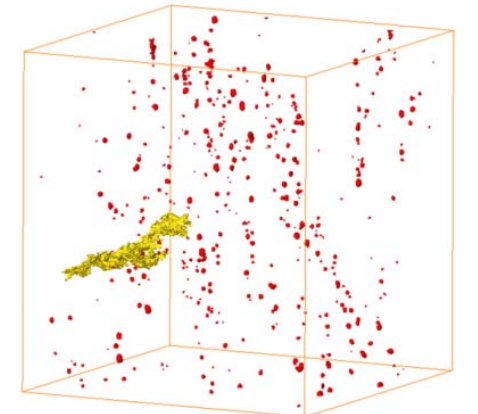

(g) 6th loading step

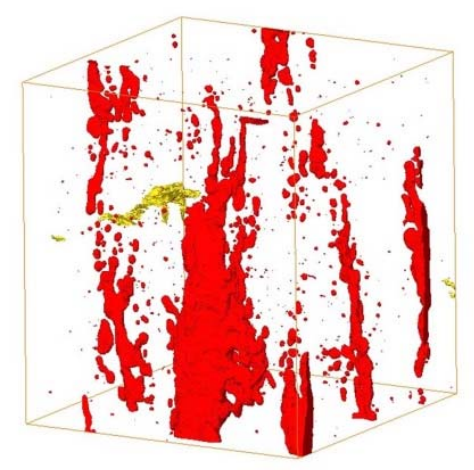

(k) 6th loading step

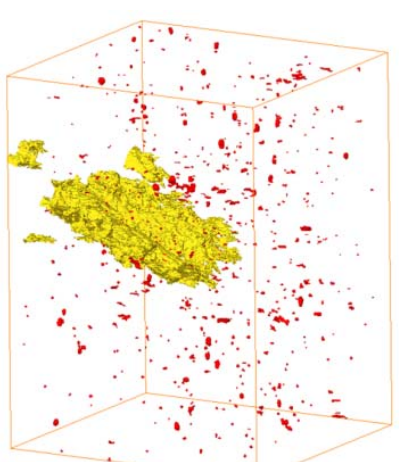

(d) 10th loading step

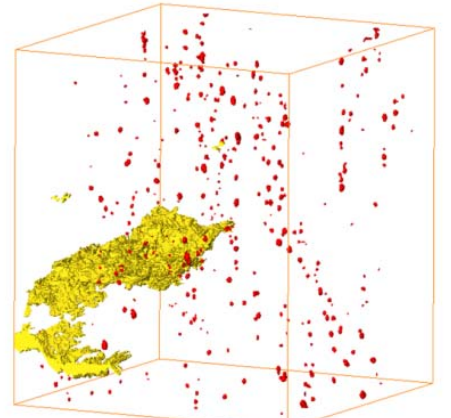

(h) 10th loading step

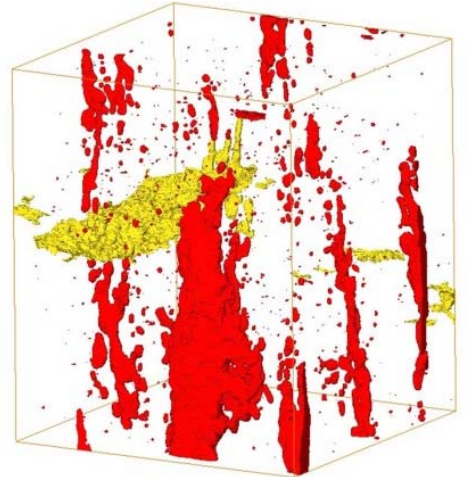

(1) 9th loading step

Fig. 8. A series of 3D rendered images during loading representing the nucleation and propagation of cracks in the materials. Micropores are shown in red, and crack in yellow, in (a) (d) for LH material, (e) (h)for MH material, and (i) (1) for $\mathrm{HH}$ material, respectively 

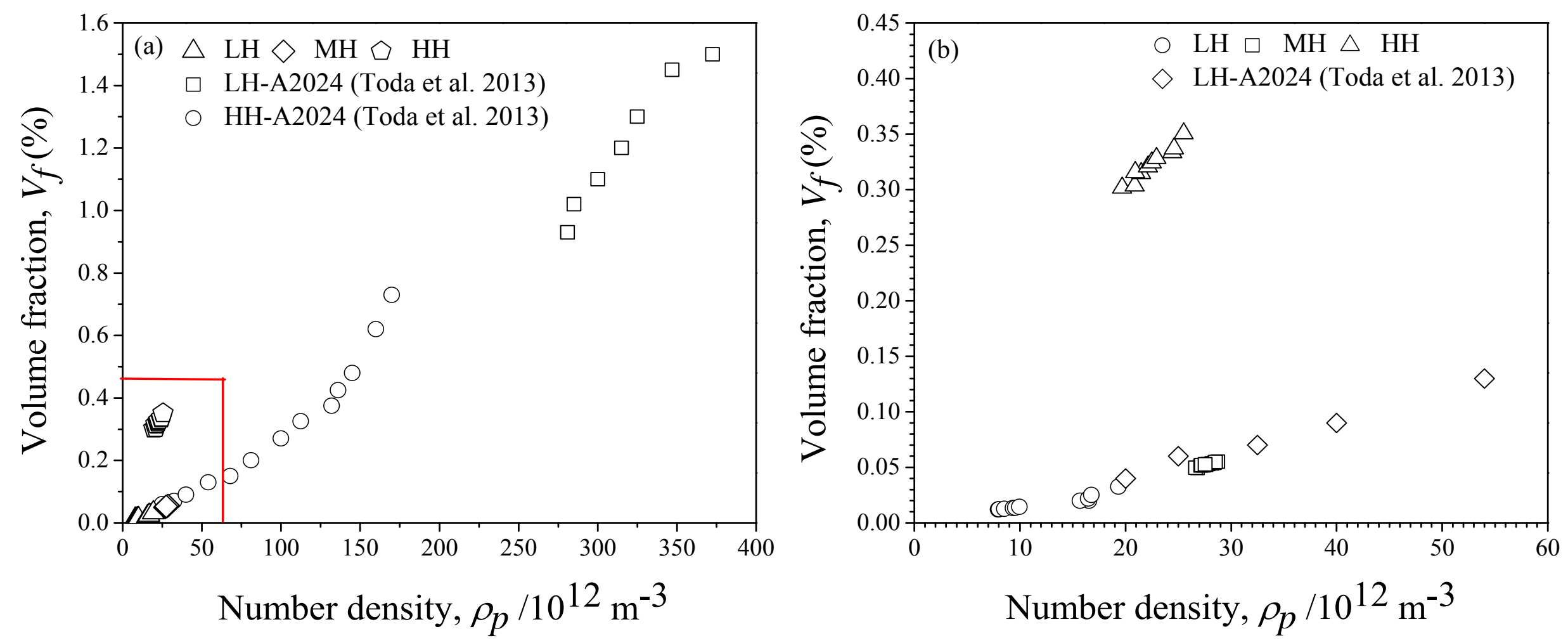

Fig. 9. Relationships between the volume fraction and number density of micropores (a) present material with A2024 aluminum alloys, (b) Magnified view of Fig (a) labeled by red rectangle 

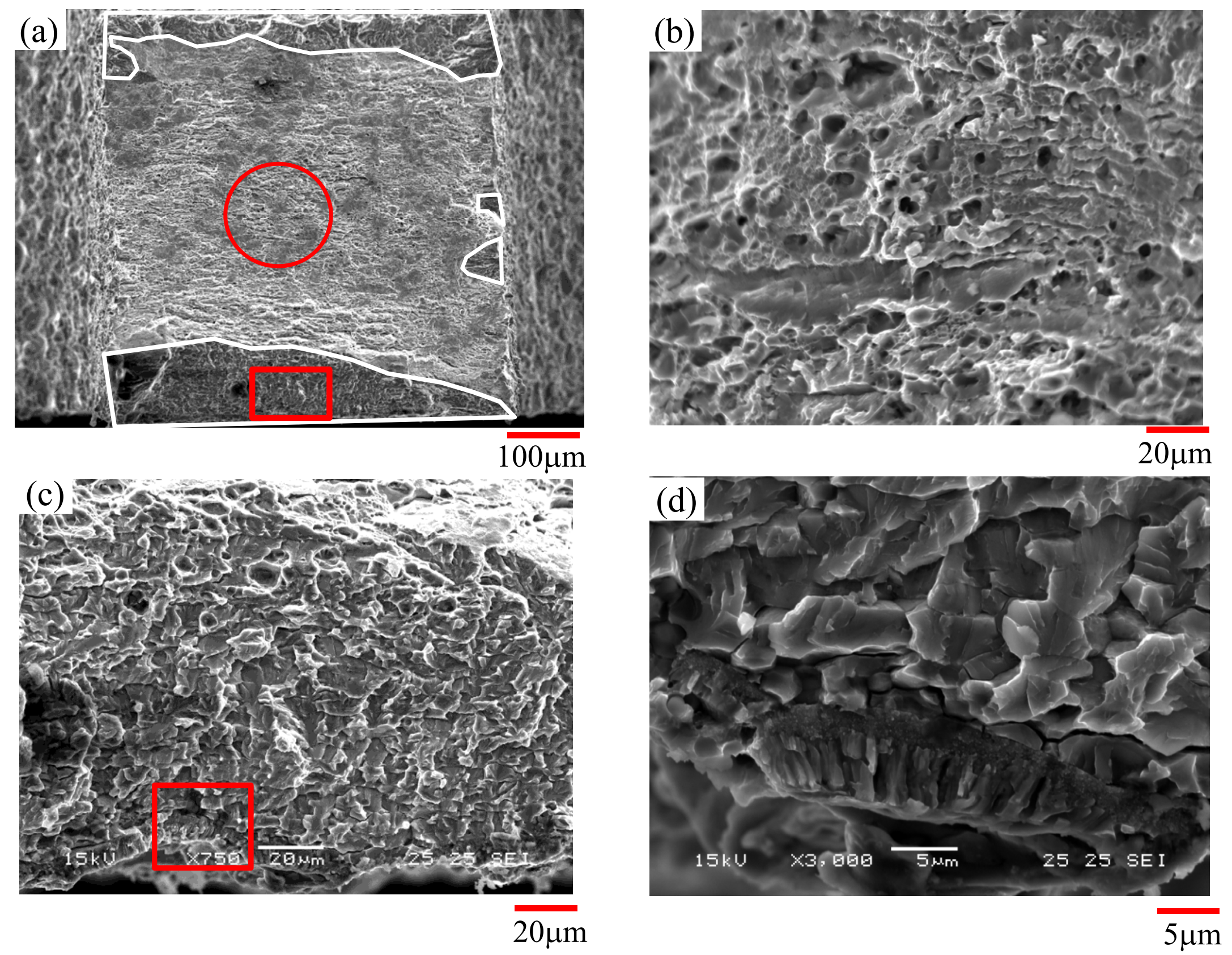

Fig. 10. SEM fractographs of material MH showing: (a) overview of the fracture surface, (b) Magnified image of the part outlined by the circle in (a), (c) Magnified image of the part outlined by the rectangle in (a), and (d) Magnified image of the part outlined by the rectangle in (c) 


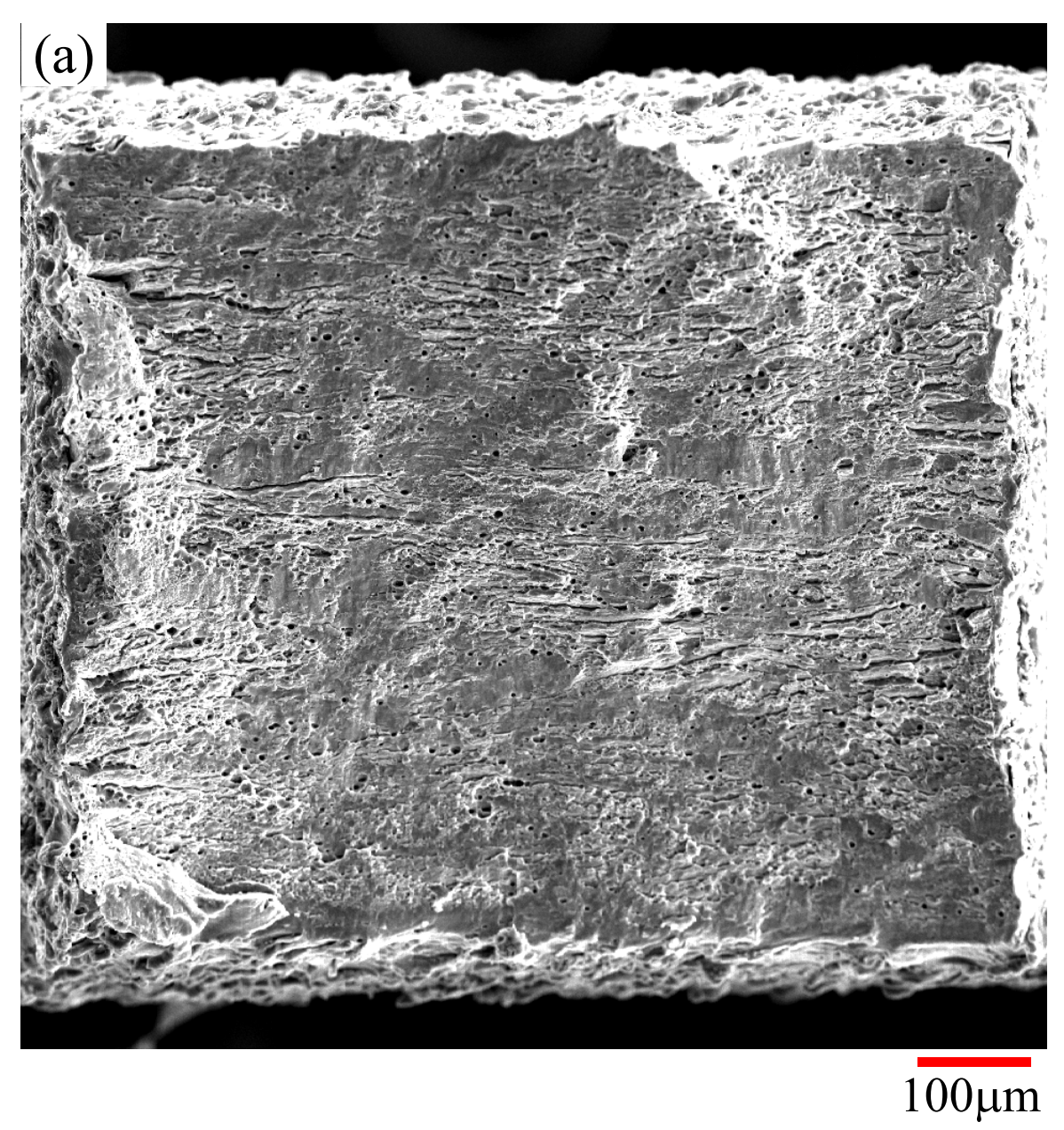

Base 7150 aluminum alloys

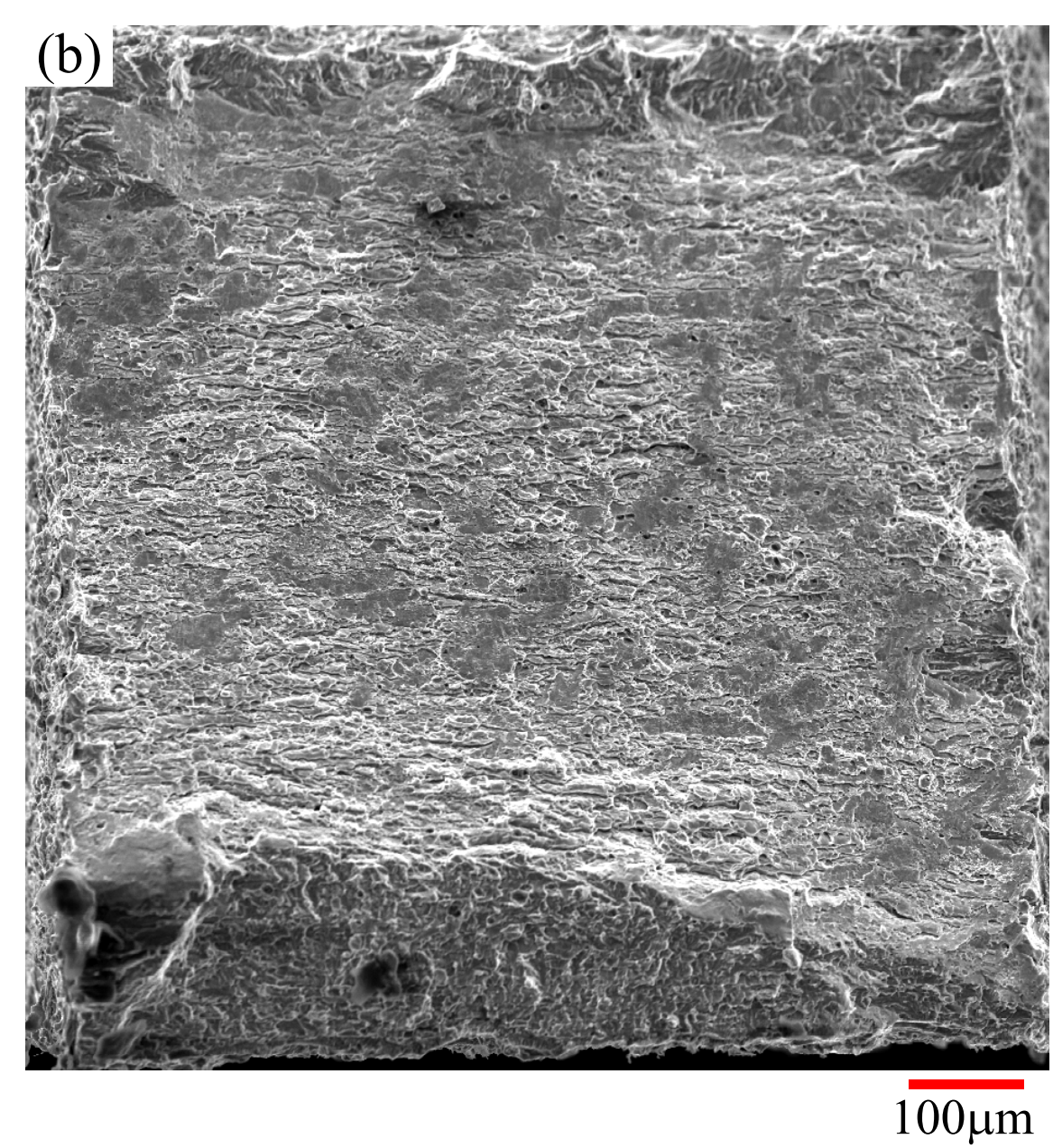

Modified 7150 aluminum alloys

Fig. 11. SEM fractographs showing: (a) overview of the fracture surface of a base 7150 aluminum alloys, (b) overview of the fracture surface of material $\mathrm{MH}$ from modified 7150 aluminum alloys 
(a)

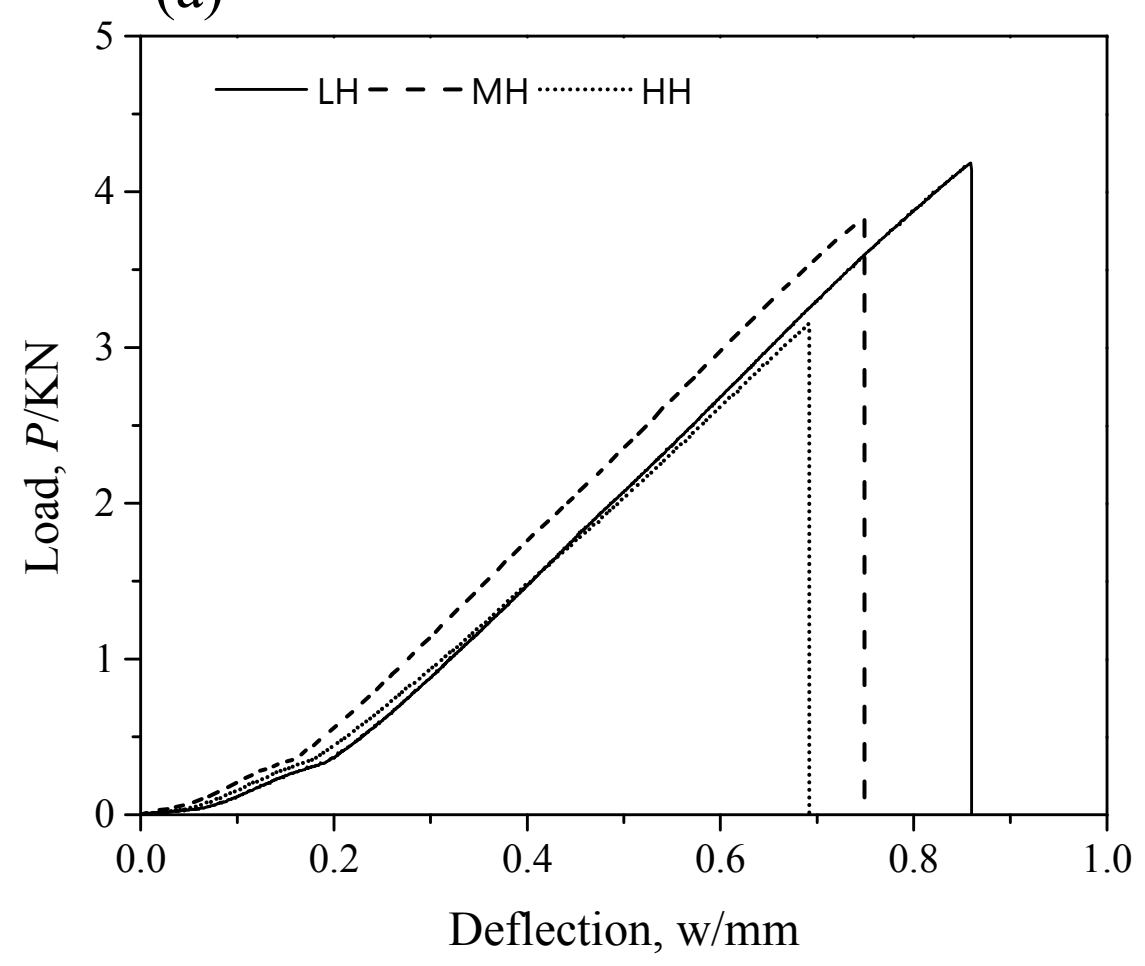

(b)

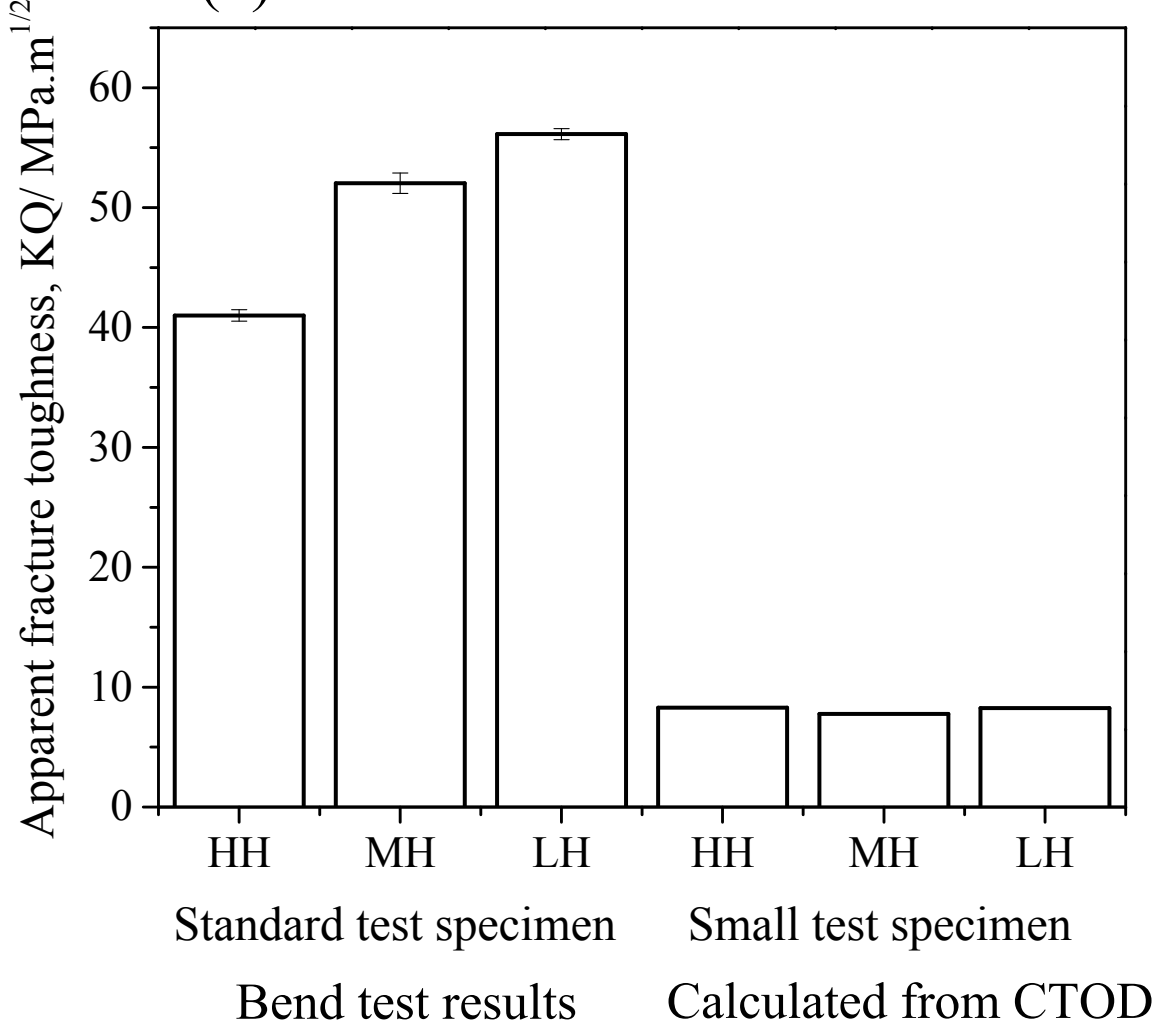

Fig. 12. (a) Load vs. Deflection curve and (b)Fracture toughness values obtained with the standard test specimens. Fracture toughness values of specimens associated with the quasi-cleavage fracture is also shown in the figure. 


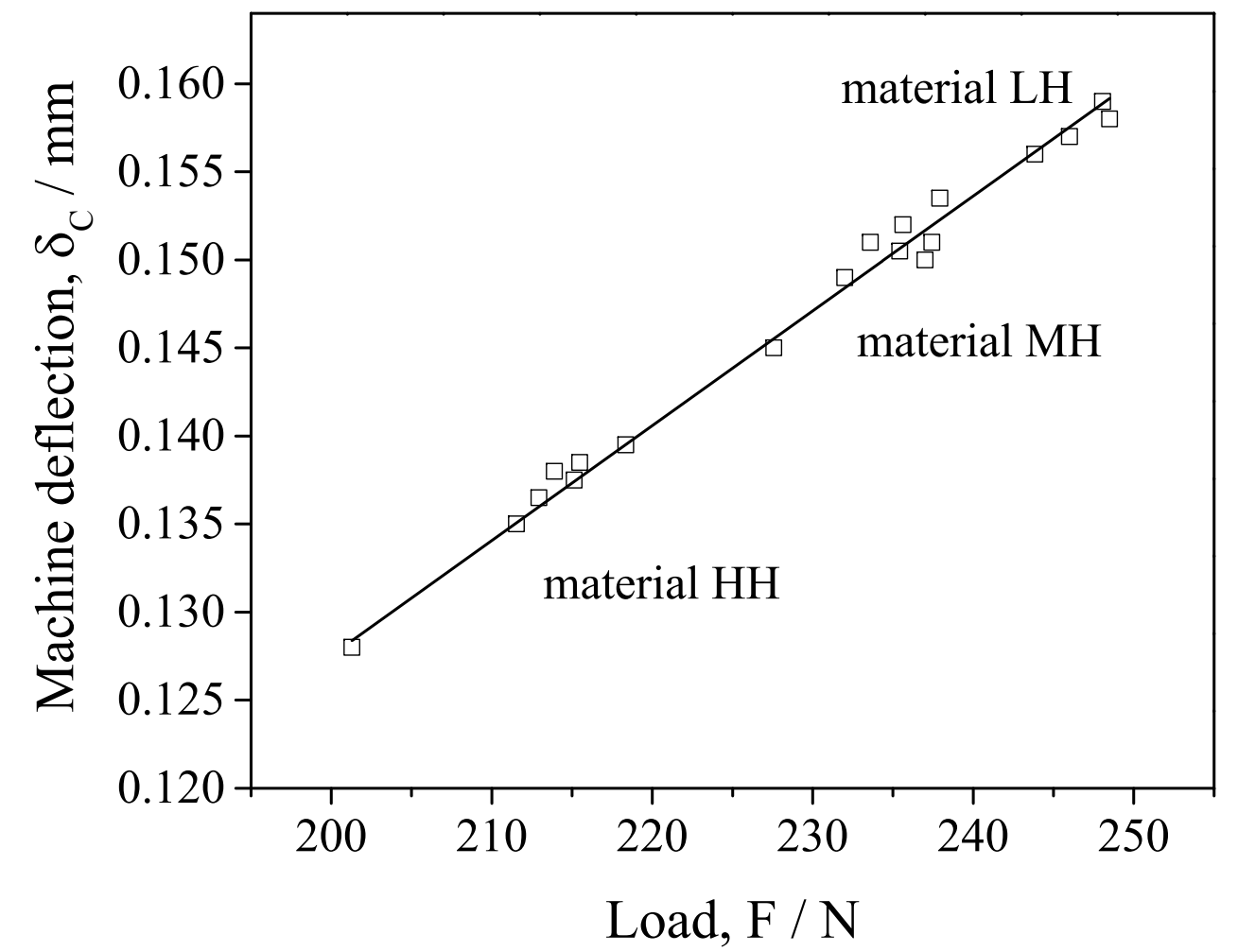

Fig. 13. Applied force-machine deflection curve 

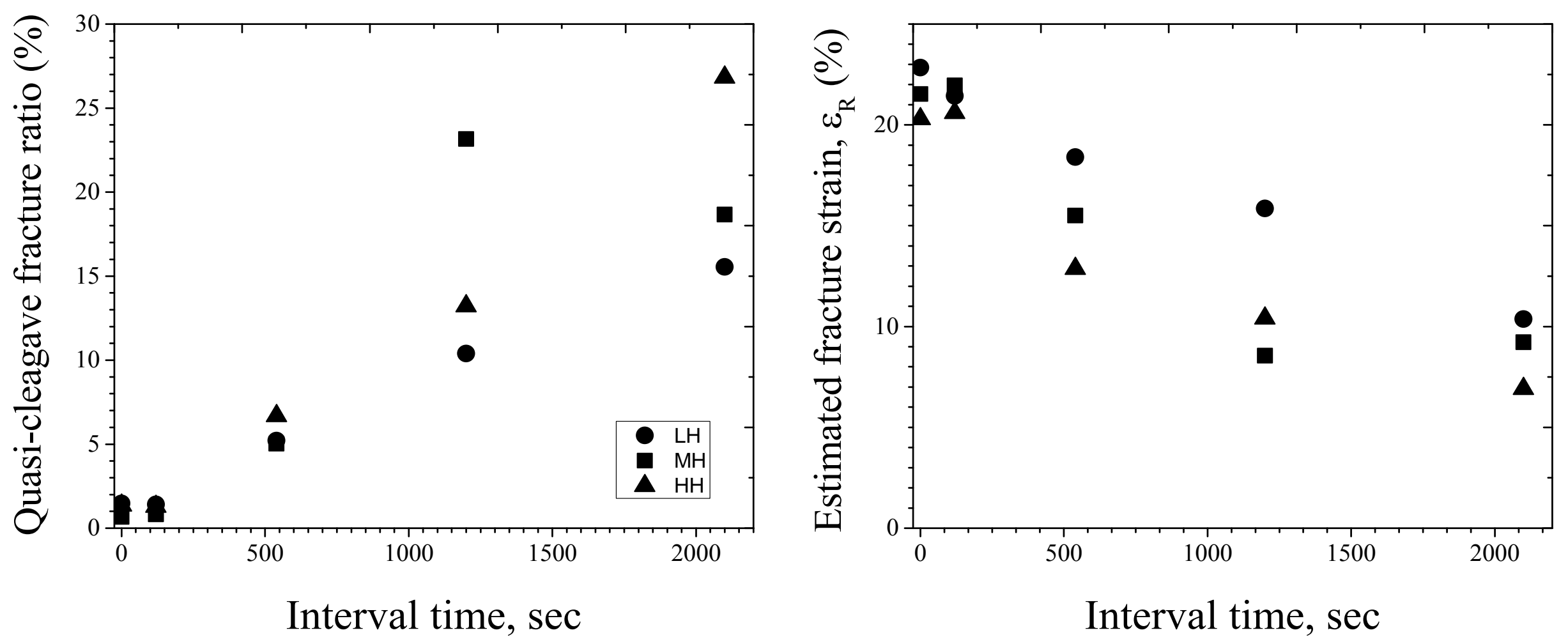

Fig. 14. (a) Quasi cleavage fracture ratio and (b) Apparent fracture strain as a function of holding time. 


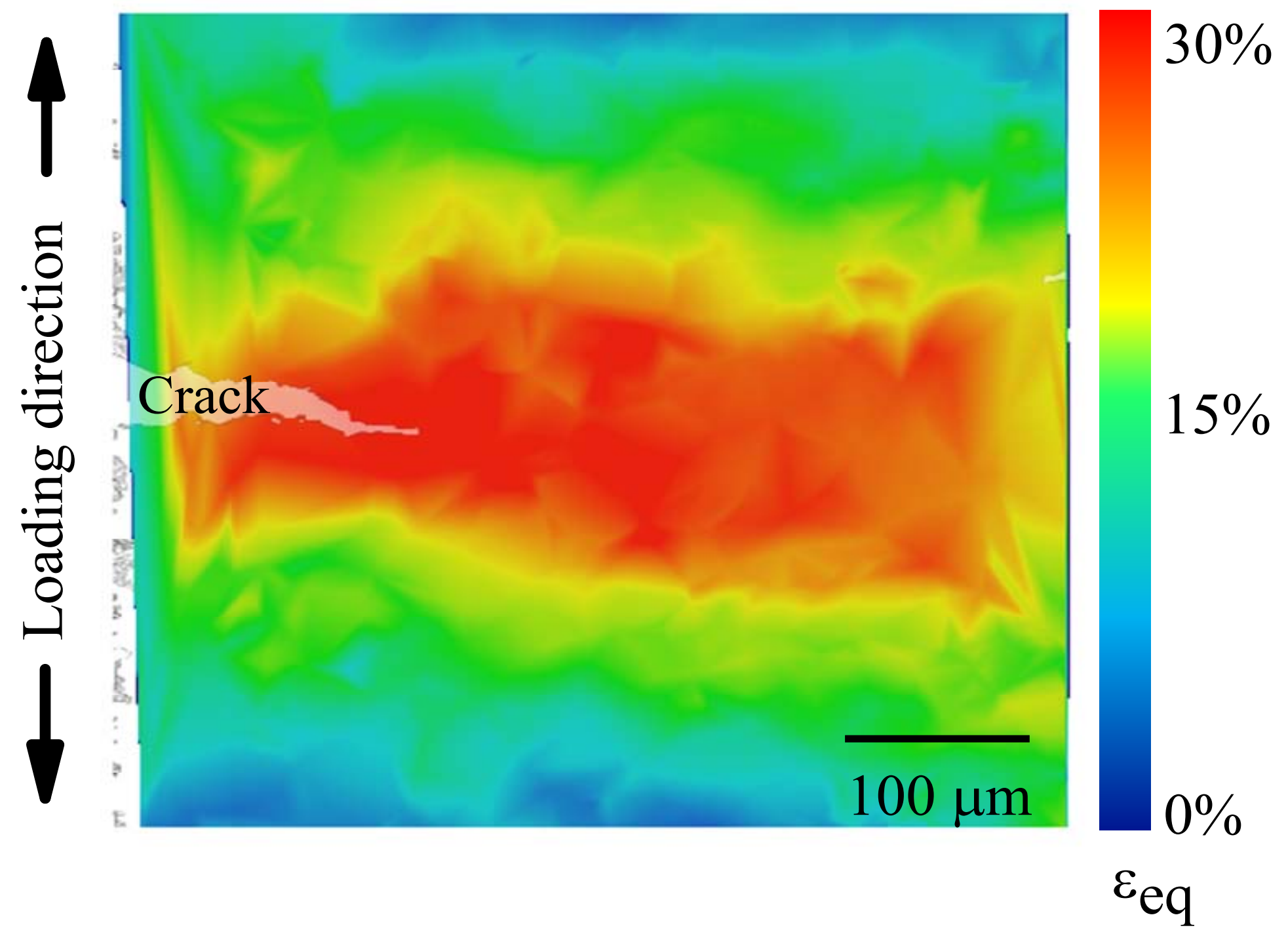

Fig. 15. Strain mapping of material LH during tensile test captured just before fracture at $\varepsilon=13.6 \%$ 


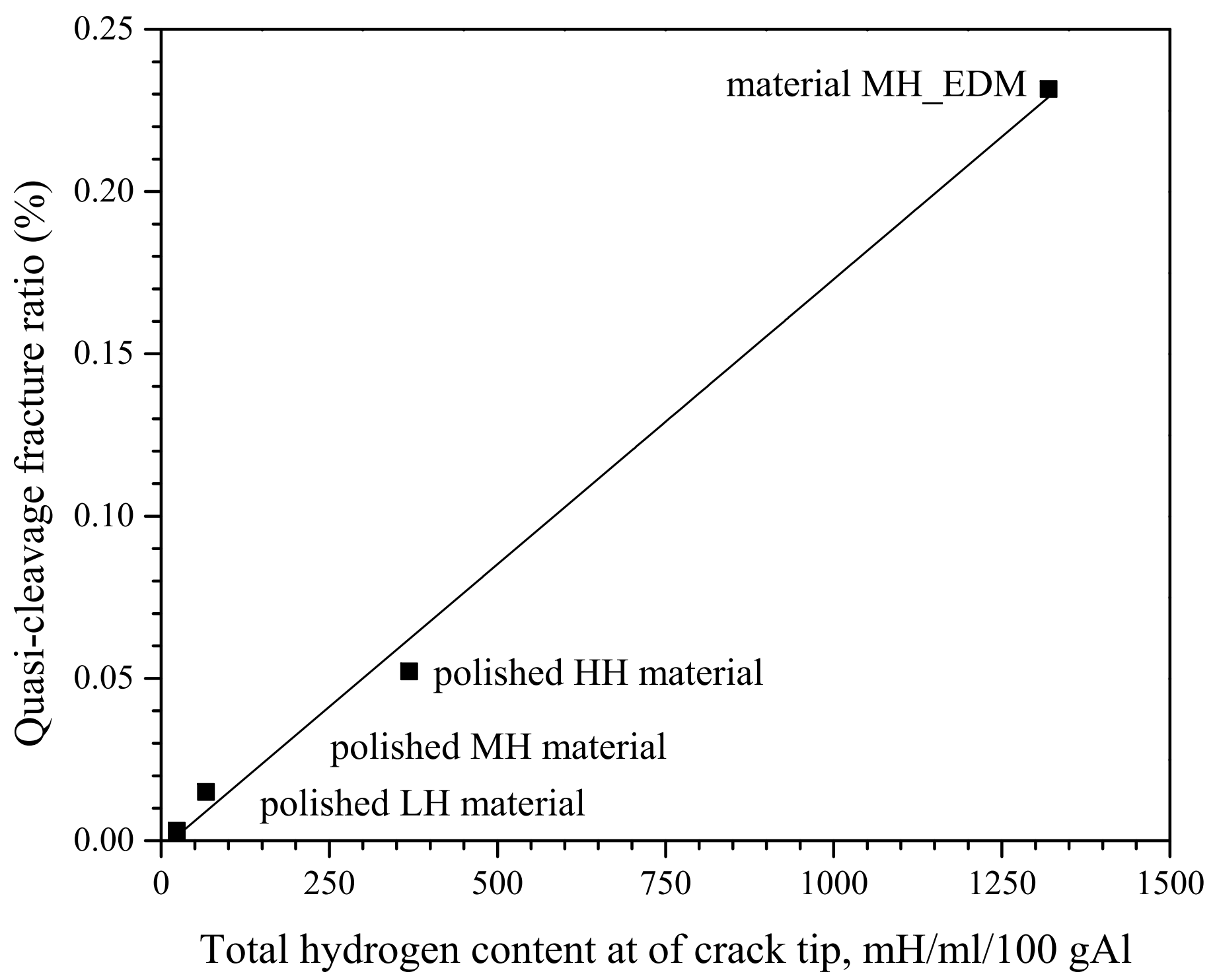

Fig. 16. Quasi cleavage fracture ratio as a function of hydrogen content 